OPEN ACCESS

Edited by:

Moncef Zouali,

Institut National de la Santé et de la

Recherche Médicale (INSERM),

France

Reviewed by:

Ben J. Gu,

University of Melbourne, Australia

Marta Olah,

Columbia University Irving Medical

Center, United States

${ }^{*}$ Correspondence:

Ping Zhang

pingz@uab.edu

Specialty section:

This article was submitted to

Molecular Innate Immunity,

a section of the journal

Frontiers in Immunology

Received: 16 November 2021

Accepted: 11 January 2022

Published: 01 February 2022

Citation:

Hao X, Li Z, Li W, Katz J, Michalek SM, Barnum SR, Pozzo-Miller L, Saito $T$, Saido TC, Wang $Q$, Roberson ED and Zhang P (2022) Periodontal Infection Aggravates C1q-Mediated

Microglial Activation and Synapse Pruning in Alzheimer's Mice.

Front. Immunol. 13:816640. doi: 10.3389/fimmu.2022.816640

\section{Periodontal Infection Aggravates C1q-Mediated Microglial Activation and Synapse Pruning in Alzheimer's Mice}

\author{
Xiaoxiao Hao ${ }^{1}$, Zhaofei $L i^{1}$, Wei $L i^{2}$, Jannet Katz ${ }^{1}$, Suzanne M. Michalek ${ }^{3}$, \\ Scott R. Barnum ${ }^{4}$, Lucas Pozzo-Miller ${ }^{2}$, Takashi Saito ${ }^{5,6}$, Takaomi C. Saido ${ }^{5}$, \\ Qin Wang ${ }^{7}$, Erik D. Roberson ${ }^{8}$ and Ping Zhang ${ }^{1 *}$
}

\footnotetext{
${ }^{1}$ Department of Pediatric Dentistry, School of Dentistry, University of Alabama at Birmingham, Birmingham, AL, United States, 2 Department of Neurobiology, School of Medicine, University of Alabama at Birmingham, Birmingham, AL, United States, ${ }^{3}$ Department of Microbiology, School of Medicine, University of Alabama at Birmingham, Birmingham, AL, United States, ${ }^{4}$ CNine Biosolutions, LLC, Birmingham, AL, United States, ${ }^{5}$ Laboratory for Proteolytic Neuroscience, RIKEN Center for Brain Science, Wako, Japan, ${ }^{6}$ Department of Neurocognitive Science, Institute of Brain Science, Nagoya City University Graduate School of Medical Sciences, Nagoya, Japan, ${ }^{7}$ Department of Cell, Developmental and Integrative Biology, School of Medicine, University of Alabama at Birmingham, Birmingham, AL, United States, ${ }^{8}$ Center for Neurodegeneration and Experimental Therapeutics, Alzheimer's Disease Center, Department of Neurology, School of Medicine, University of Alabama at Birmingham, Birmingham, AL, United States
}

Periodontitis is a dysbiotic infectious disease that leads to the destruction of tooth supporting tissues. There is increasing evidence that periodontitis may affect the development and severity of Alzheimer's disease (AD). However, the mechanism(s) by which periodontal infection impacts the neurodegenerative process in $A D$ remains unclear. In the present study, using an amyloid precursor protein (APP) knock-in (App $\mathrm{KI})$ AD mouse model, we showed that oral infection with Porphyromonas gingivalis ( $\mathrm{Pg}$ ), a keystone pathogen of periodontitis, worsened behavioral and cognitive impairment and accelerated amyloid beta $(A \beta)$ accumulation in $A D$ mice, thus unquestionably and significantly aggravating $A D$. We also provide new evidence that the neuroinflammatory status established by $A D$, is greatly complicated by periodontal infection and the consequential entry of $\mathrm{Pg}$ into the brain via $\mathrm{A} \beta$-primed microglial activation, and that $\mathrm{Pg}$-induced brain overactivation of complement $\mathrm{C} 1 \mathrm{q}$ is critical for periodontitis-associated acceleration of $\mathrm{AD}$ progression by amplifying microglial activation, neuroinflammation, and tagging synapses for microglial engulfment. Our study renders support for the importance of periodontal infection in the innate immune regulation of $A D$ and the possibility of targeting microbial etiology and periodontal treatment to ameliorate the clinical manifestation of $A D$ and lower $A D$ prevalence.

Keywords: Periodontitis, Porphyromonas gingivalis, Alzheimer's disease, microglia, complement C1q, synapse loss 


\section{INTRODUCTION}

Alzheimer's disease (AD), an age-related neurodegenerative disease of the central nervous system (CNS), is the most common cause of dementia and is characterized by progressive and irreversible decline in behavioral and cognitive function (1). $\mathrm{AD}$ affects more than 50 million people globally and is the sixth leading cause of death in the US (2). Despite great efforts, the cellular and molecular mechanisms underlying $\mathrm{AD}$ pathogenesis are not fully understood, and there is no effective therapy to cure or ameliorate this devastating disease $(3,4)$. Therefore, there is an urgent need to identify modifiable risk factors that impact $\mathrm{AD}$, so that strategies that mitigate $\mathrm{AD}$ severity are implemented.

Periodontitis is a chronic infectious disease characterized by periodontal inflammation and alveolar bone loss, and is the primary cause of tooth loss in adults (5). Increasing evidence suggests that periodontitis is associated with a diversity of systemic disorders, including AD (6). In this regard, epidemiological studies indicate that there is a positive correlation between cognitive decline in $\mathrm{AD}$ patients and periodontitis $(7,8)$. In addition, periodontitis has been shown to positively associate with brain amyloid plaque development, a pathological hallmark of $\mathrm{AD}$, in elderly and $\mathrm{AD}$ patients (9). Furthermore, Porphyromonas gingivalis (Pg), a keystone pathogen of periodontitis, as well as its virulence factors lipopolysaccharide (LPS) and gingipains, have been detected in the post-mortem brains from $\mathrm{AD}$ patients $(10,11)$. However, mechanisms underlying the association between periodontitis and the development of $\mathrm{AD}$ is lacking.

Microglia cells are the most common innate immune cells in the CNS and play a central role in maintaining the immune homeostasis in the brain (12). However, microglia overactivation can lead to sustained neuroinflammation and contribute to the pathogenesis of neurodegenerative diseases (13). The complement system, also known as the complement cascade, represents a major part of innate immunity and comprises an interactive network of soluble and membrane-associated proteins that activate, amplify, and regulate immunity and inflammation $(14,15)$. Although the complement system provides rapid recognition and response to dangers that threaten the host, a dysregulated complement system can also mediate destructive inflammation (15). Clinical and experimental studies have suggested the involvement of periodontal complement activation in the pathogenesis of periodontitis $(6,16,17)$. There is also emerging evidence suggesting that aberrant complement activation is involved in $\mathrm{AD}$ development (18-20). However, the role complement and microglial activation in the association of periodontitis and $\mathrm{AD}$ is not clear.

In this study, using the amyloid precursor protein (APP) knock-in (App KI) mouse model, we sought to determine the effect of Pg infection on the progressive neurodegeneration of $\mathrm{AD}$ and the involvement of complement $\mathrm{Clq}$ in the process. We demonstrated the importance of micorglia and complement component $\mathrm{C} 1 \mathrm{q}$ in the aggravation of $\mathrm{AD}$ neuropathologies in the presence of periodontal infection. Our study suggests a "twohit" model of Pg-mediated aggravation of AD, with amyloid $\beta$
(A $\beta$ ) accumulation as the first hit, and Pg brain invasion as the second hit to faciliate synaspse loss.

\section{MATERIALS AND METHODS}

\section{Mice}

C57BL/6 wild-type (WT) mice were obtained from Jackson Laboratories (Ellsworth, ME, USA). App $p^{N L-G-F / N L-G-F}$ knock-in (App KI) mice (21) that carry the APP Swedish (KM670/671NL), Iberian (I716F), and Arctic (E693G) mutations were originally obtained under a material transfer agreement from Dr. Takaomi Saido (RIKEN Brain Science Institute, Japan), and had been backcrossed for more than 12 generations to obtain the C57BL/6 background. Animals were housed in an environmentally controlled facility at the University of Alabama at Birmingham (UAB), protocols for all animal studies were approved by the UAB Institutional Animal Care and Use Committee.

\section{Bacterial Culture and Infection Model}

$\mathrm{Pg}$ ATCC 33277 was cultured in trypticase soy broth (BD Biosciences) containing $1 \%$ yeast extract, $5 \mu \mathrm{g} / \mathrm{mL}$ hemin, and $1 \mu \mathrm{g} / \mathrm{mL}$ menadione and grown at $37^{\circ} \mathrm{C}$ in an anaerobic atmosphere of $10 \% \mathrm{H} 2,5 \% \mathrm{CO} 2$, and $85 \% \mathrm{~N} 2$ (22). Pg infection was carried out as previously described (23) with some modifications (Figure 1A). Briefly, age- and sex-matched WT and App KI mice ( 6 weeks of age) were randomly assigned to control or Pg-infected groups. Mice were provided drinking water containing kanamycin $(1 \mathrm{mg} / \mathrm{ml})$ for 7 days to reduce the indigenous oral microflora. After removing antibiotics for 3 days, experimental mice were given $100 \mu \mathrm{l}$ of freshly harvested Pg $\left(10^{10} \mathrm{CFU} / \mathrm{ml}\right)$ in $2 \%$ carboxymethylcellulose (CMC) and control groups received $100 \mu \mathrm{l}$ of $2 \% \mathrm{CMC}$ by oral gavage 3 times per week for 6 weeks. Mice were refrained from food and water intake for 1 hour (h) after infection.

\section{Evaluation of Alveolar Bone Loss and Periodontal Inflammation}

Groups of mice were sacrificed 2 weeks post the last dose of Pg to assess the establishment of periodontitis. Specifically, the right maxilla from each mouse was fixed and then stained with $1 \%$ methylene blue (24). The distance between the cementumenamel junction (CEJ) and the alveolar bone crest $(\mathrm{ABC})$ was measured at a total of seven buccal sites with the assistance of an Image J analysis system (NCBI). To assess periodontal inflammation, gingival tissues around the left maxillary molars were collected, homogenized, and analyzed for inflammatory gene expression as described below.

\section{Behavioral Tests}

Three behavioral tests were carried out at 4, 6 and 10 months of age (Figure 1A). On each testing day, groups of mice were transferred to the testing room $1 \mathrm{~h}$ before testing for acclimatization. On day 1 of indicated age, mice were tested for general locomotor activity and exploration habits in the open field (OF) test (25). On day 2, elevated zero maze (EZM) was conducted to evaluate anxiety-related behavior (26). After resting 
A

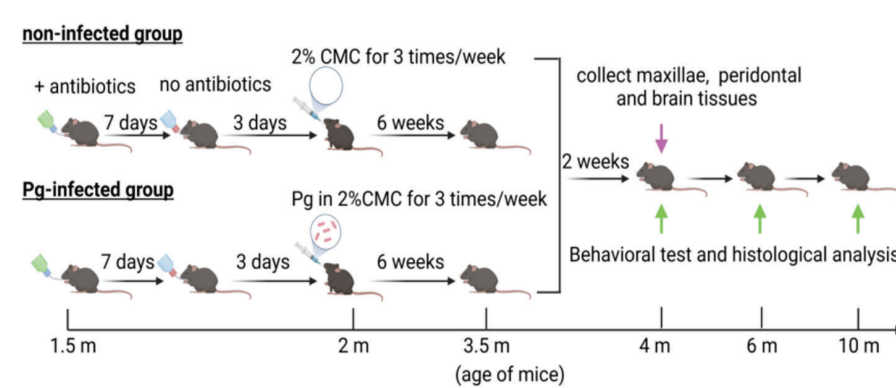

B

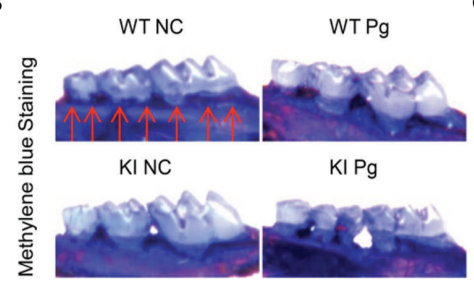

C

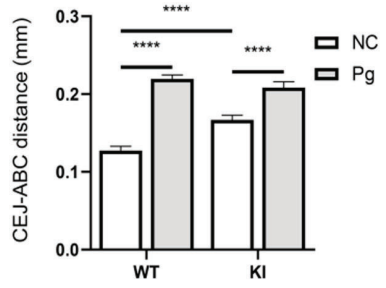

D

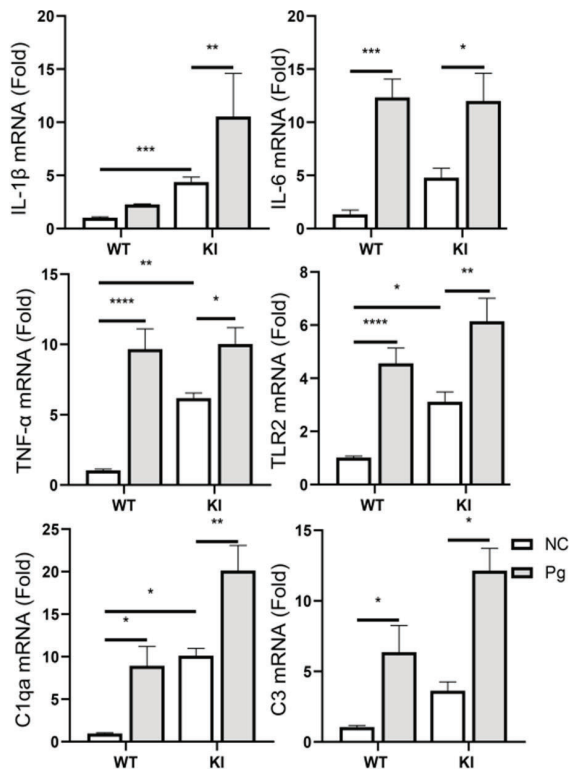

FIGURE 1 | Pg-induced alveolar bone loss and periodontal inflammation in App KI and WT mice following oral infection. (A) Schematic of the experimental design used in this study. m, month. (B) Representative methylene blue-stained maxillae from non-infected (NC) and Pg-infected WT and App KI mice (n=9 mice/group). Bone loss was assessed in a total of 7 buccal sites (red arrows) per mouse. (C) Alveolar bone loss in Pg-infected and non-infected WT and App KI mice; mm, millimeter; CEJ-ABC, cemento-enamel junction-alveolar bone crest. (D) Inflammatory cytokine and complement gene expression in gingival tissues from non-infected and Pg-infected WT and App KI mice. Gene expression was normalized to GAPDH and expressed as fold changes. Samples were done in duplicate ( $\mathrm{n}=7$ mice/ group). Data are expressed as mean \pm SEM. ${ }^{\star} P<0.05,{ }^{\star \star} P<0.01,{ }^{\star \star \star} P<0.001,{ }^{\star \star \star \star} P<0.0001$, by two-way ANOVA followed with Tukey correction.

for a day, mice were subjected to Morris water maze (MWM) for 5 days followed by probe trial to assess learning performance and reference memory, respectively (27). All behavioral tests were conducted during the light phase of the diurnal cycle and data were collected using an EthoVision video tracking system (Noduls).

\section{Evaluation of $A \beta$ Peptide Accumulation in the Brain}

To evaluate brain $A \beta$ peptide accumulation, groups of mice were anesthetized and perfused with PBS (28). Brains were collected after perfusion and one side hemispheres were dissected, and cortices and hippocampi were isolated and homogenized in carbonate buffer supplemented with proteinase inhibitor cocktail (29). The supernatants were collected as the carbonate-soluble parts. The pellets were subjected to further homogenization in guanidine solution, and the supernatants were collected as the carbonate-insoluble fractions. The levels of hA $\beta 42$ in the soluble and insoluble fractions were measured using a hA $\beta 42$-specific ELISA kit (Invitrogen, \#KHB3442), following the manufacturer's instructions. The other side hemispheres were fixed in $4 \%$ paraformaldehyde (PFA) and used for immunohistochemistry staining as described below.

\section{Immunohistochemistry and Immunofluorescence Staining}

Formalin-fixed, paraffin-embedded hemispheres were sectioned in the coronal plane at $7 \mu \mathrm{m}$. For analysis of $A \beta$ plaque depositions, sections were treated with $70 \%$ formic acid after de-paraffinization and rehydration (30). Following antigen retrieval, sections were probed with an anti-A $\beta$ antibody (6E10) (Biolegend, \#803004) followed by HRP-labeled secondary antibody (JacksonImmuno, \#711-035-150). A Thyramide signal amplification kit (Perkin Elmer) was used to enhance the sensitivity of detection. Nuclei were stained with DAPI. For detection of microglial and C1q activation and colocalization, sections were stained with antibodies against IBA1 (Cell signaling, \#17198), and/or C1qa (Abcam, \#ab182451). Data were acquired with a KEYENCE BZ800 microscope and images were processed using an ImageJ analysis system. To examine synapse loss, mice were perfused with PBS as described above, and then further perfused with 50-60 $\mathrm{ml} 4 \% \mathrm{PFA} / \mathrm{PBS}$ to facilitate rapid and even fixation (31). Brain sectioned at $35 \mu \mathrm{m}$ thickness were prepared and free-floating sections were stained for PSD95 (Cell signaling, \#3450S), SNAP25 (Abcam, \#ab109105), or co-stained for IBA1 or C1q. For quantitative analysis of synapses and the presence of $\mathrm{Clq}$ at the synapses, regions of interest (ROI) were acquired with a Zeiss LSM-800 Airyscan confocal microscope and analyzed using Puncta analyzer (Duke University) run in the ImageJ analysis system (32). About 50-100 synapses (SNAP25 ${ }^{+}$or PSD95 ${ }^{+}$puncta) were recorded per mouse per ROI and the number of $\mathrm{Clqa}^{+}$ particles present per synapse was scored. For microglia engulfment, brain sections were imaged up to $25 \mathrm{Z}$-stacks at $0.33 \mu \mathrm{m}$ steps (32). Ten to fifteen microglia within the hippocampus CA1 region and cortex, per mouse, were randomly selected and analyzed. 


\section{Genomic DNA Extraction of Brain Tissue and PCR Analysis of Pg}

Genomic DNA (gDNA) was extracted from mice brain tissues using a Blood and Tissue Kit (Qiagen), followed by standard PCR and qPCR to assess for Pg specific humY gene and $16 \mathrm{~S}$ ribosomal RNA (16S rRNA), respectively $(33,34)$. Primer sequences are listed in Table S1.

\section{Fluorescence In Situ Hybridization (FISH) for Detection of Pg in Mouse Brain}

FISH was conducted using probes specific to Pg 16S rRNA gene sequence on rehydrated brain sections, as previously described (35). Briefly, after deparaffinization and antigen retrieval, brain sections were probed with 5 pmol of Pg $16 \mathrm{~S}$ rRNA-specific oligonucleotide POG (SILVA, ribosomal RNA database) 5'CAA TAC TCG TAT CGC CCG TTA TTC-3' labeled with fluorescein isothiocyanate (synthesized at Integrated DNA Technologies). Data were acquired with a KEYENCE BZ-800 microscope and images were processed using ImageJ.

\section{Quantitative Reverse Transcription PCR (RT-qPCR)}

To analyze the gene expression of inflammatory cytokines and complement components in gingival tissues, brain tissues, or cultured microglia cells, tissues or cells were homogenized and total RNA were extracted using Direct-zol RNA Miniprep kit (ZYMO Research, \#R2052). cDNA was synthesized using a PrimeScript RT Reagent kit (Takara, \#RR037) using equal amount of RNA. RT-qPCR was performed using an ABI Prism 7500 fast system (Applied Biosystems) with the 2x qPCR Master Mix (NEB, \#M3003). All primers information is listed in Table S1.

\section{Complement Component ELISA}

Brain tissues were collected from groups of mice, weighed and homogenized in PBS with protease inhibitors cocktail. Homogenized brain tissues then underwent 3 freeze-thaw cycles and supernantants were collected after centrifugation. The levels of C1qa and C3 in the supernatants were assessed by ELISA according to the manufacturer's instructions (Mybiosource, \#MBS921993 and \#MBS763294).

\section{Preparation of Oligomeric $A \beta(A \beta O)$}

$\mathrm{A} \beta \mathrm{o}$ was prepared as previously described (36). Briefly, the $\mathrm{A} \beta_{1-42}$ synthetic peptide (Bachem, \#4045866) was suspended in 100\% 1,1,1,3,3,3 hexafluoro-2-propanol (HFIP) and then incubated for complete solubilization under shaking at $37^{\circ} \mathrm{C}$ for $2 \mathrm{~h}$. HFIP/ peptide was dried in a flammable hood for 6-8 h, and resuspended in DMSO. An oligomeric form of the peptide was further generated by pre-incubation for $24-72 \mathrm{~h}$ at $37^{\circ} \mathrm{C}$ before adding to the cultures.

\section{Primary Microglia Culture}

Primary microglia were generated from cerebral cortices of WT newborn pups (postnatal day 0), as previously described (37). Briefly, brains were harvested, and the meninges were removed.
Cortices and hippocampi were then dissected into small pieces and triturated in Hanks' balanced salt solution (HBSS) and cultured in Dulbecco's modified eagle medium (DMEM) containing $16 \mathrm{mM}$ HEPES, 1x non-essential amino acids, 1x Lglutamine, $10 \%$ fetal bovine serum (FBS) and $50 \mu \mathrm{g} / \mathrm{ml}$ gentamicin for 10 days until confluent. Microglia were collected and then re-suspended in fresh media and cultured for $18-24 \mathrm{~h}$ prior to stimulation. Microglia $\left(1 \times 10^{6}\right)$ were treated with $\mathrm{A} \beta \mathrm{o}(0.1 \mu \mathrm{M}, 1 \mu \mathrm{M}$ and $10 \mu \mathrm{M}), \mathrm{Pg}(\mathrm{MOI}=50), \mathrm{Pg}$ plus $\mathrm{A} \beta \mathrm{o}$, or pre-treated with $\mathrm{A} \beta \mathrm{o}$ for $6 \mathrm{~h}$ followed by $24 \mathrm{~h} \mathrm{Pg}$ stimulation. To test the role of complement activation in Pginduced inflammatory responses in microglia, microglia were pre-incubated with $100 \mathrm{ng} / \mathrm{ml} \mathrm{C1}$ esterase inhibitor (C1-INH, Sigma, \#E0518) for $4 \mathrm{~h}$, followed by A $\beta$ o treatment for $6 \mathrm{~h}$, and then by Pg stimulation for $24 \mathrm{~h}$. To specially test the effect of $\mathrm{Clq}$ on Pg-induced inflammatory responses, microglia cells were transfected with lentivirus pLKO.1 puro containing C1qa shRNA (target sequence CCGGCTTCTATTACTTCAAC TCGAG) or scramble RNA. Successful transfection was verified by analyzing C1qa mRNA and protein expression in microglia. The stably transfected microglia were then stimulated with Pg $(\mathrm{MOI}=50)$ for $24 \mathrm{~h}$. The cells were then collected, and RNA was extracted for analyzing the gene expression of inflammatory cytokines and complement components by RT-qPCR.

\section{Microglia-Neuron Co-Culture}

Primary neuronal cultures were prepared from the cortices of WT newborn mice using a Pierce ${ }^{\mathrm{TM}}$ primary neuron isolation kit (ThermoFisher, \#88280). Neurons were used after 13-14 days of in vitro culturing (38). Primary microglia expressing C1qa shRNA or scramble vector were pretreated with Pg $(\mathrm{MOI}=50)$ for $4 \mathrm{~h}$ or left untreated, and then added to the neuron cultures (neuron: microglia ratio 3:1) (37). After $24 \mathrm{~h}$, microglia cells were sorted from the co-cultures by FACS. The presence of synapses in microglia was analyzed by western blotting. To visualize microglia elimination of synapses, co-cultured cells were stained for IBA1 and PSD95, and then imaged on a Zeiss LSM-800 Airyscan confocal microscope as described above. Eight to ten microglia were analyzed per well, and the number of PSD95 puncta, as well as the puncta within microglia were quantified.

\section{Western Blotting}

Equal amount of proteins $(30 \mu \mathrm{g} /$ sample $)$ from sorted microglial lysates were run on 4\%-15\% mini-protean TGX stain-free precast gels (Bio-Rad) and electrotransferred to PVDF membranes (Bio$\mathrm{Rad})$. Membranes were probed with specifc antibodies against C1qa (Santa Cruz, \#sc-58920), PSD95 (Santa Cruz, \#sc-32290), NeuN (Abcam, \#ab104224), and Tubulin (Cell signaling, \#2148). Membranes were visualized using an Odyssey infrared Imaging system (LI-COR) and processed on Image J software.

\section{Statistical Analysis}

All data are expressed as mean \pm SEM and statistical significance was analyzed using GraphPad Prism (version 8.0.2, GraphPad Software Inc., San Diego, CA). One-tailed, unpaired Student $t$ - 
tests were used for comparison between two groups. One-way ANOVA or two-way ANOVA followed by Tukey's correction were used for analysis of more than two groups. A $P$ value less than 0.05 was considered as significant.

\section{RESULTS}

\section{Pg Infection Induces Alveolar Bone Loss and Increases Complement Activation in Periodontal Tissues}

Following Pg infection, significantly increased alveolar bone loss were seen at 4 months of age in WT and App KI mice, when compared with their respective non-infected controls (Figures 1B, C). In addition, increased levels of Toll-like receptor 2 (TLR2) and inflammatory cytokine (IL-1 $\beta$, IL-6 and TNF- $\alpha$ ) gene expression were detected in the gingival tissues of WT and App KI mice following Pg infection (Figure 1D). Furthermore, $\mathrm{Pg}$ infection significantly increased the gene expression of $\mathrm{C} 1 \mathrm{qa}$, the subunit $\mathrm{A}$ of the initiating protein $\mathrm{C} 1 \mathrm{q}$ of the classical complement pathway, and C3, the central component of the complement system (15), in the gingival tissues of App KI and WT mice (Figure 1D). Noteworthy, without $\mathrm{Pg}$ infection, higher levels of inflammatory cytokine and complement gene expression, as well as alveolar bone loss, were seen in App KI mice than in WT mice, indicating that AD mice have a higher baseline of periodontal inflammation.

\section{Pg Infection Accelerates the Progression of Cognitive and Behavioral Impairment in App KI Mice}

The main clinical symptom of $\mathrm{AD}$ is a decline in memory and cognitive function (39). Although associations between periodontitis and $\mathrm{AD}$ have been made, conclusive evidence of the influence of periodontitis on $\mathrm{AD}$ has not been clearly established. To assess the impact of periodontitis on the development of cognitive and behavioral impairment, behavioral tests were carried out at three time points (Figure 1A). We did not observe any significant behavior changes between any of the groups at 4 months of age (data not shown). However, at 6 months of age, compared to noninfected App KI mice, Pg-infected App KI mice showed significantly increased locomotor activity by OF test (Figure 2A), increased anxiety-related behavior by EZM test (Figure 2B), and impaired spatial learning and memory by MWW test and probe trial (Figures 2C, D). No significant difference was observed in WT mice with or without $\mathrm{Pg}$ infection, or between non-infected WT and App KI mice. At 10 months of age, non-infected App KI mice developed clear deficits in the MWM test when compared with non-infected WT mice (Figures 2E, F). In addition, Pg infection significantly increased the cognitive deficits in App KI mice. These results demonstrate that periodontal infection accelerates the progression of cognition and behavioral impairment in $\mathrm{AD}$ mice.
A

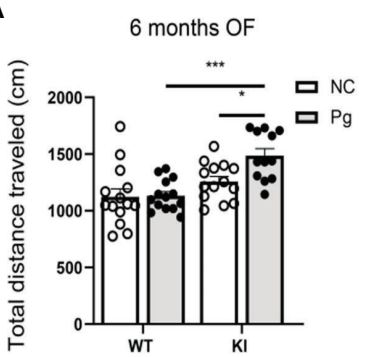

D

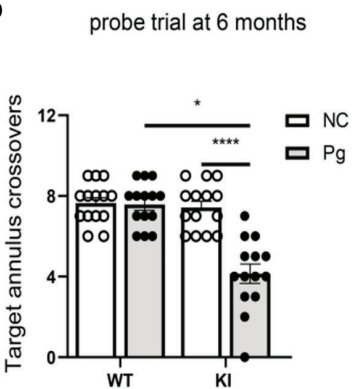

B

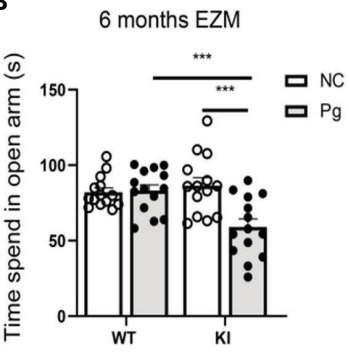

C
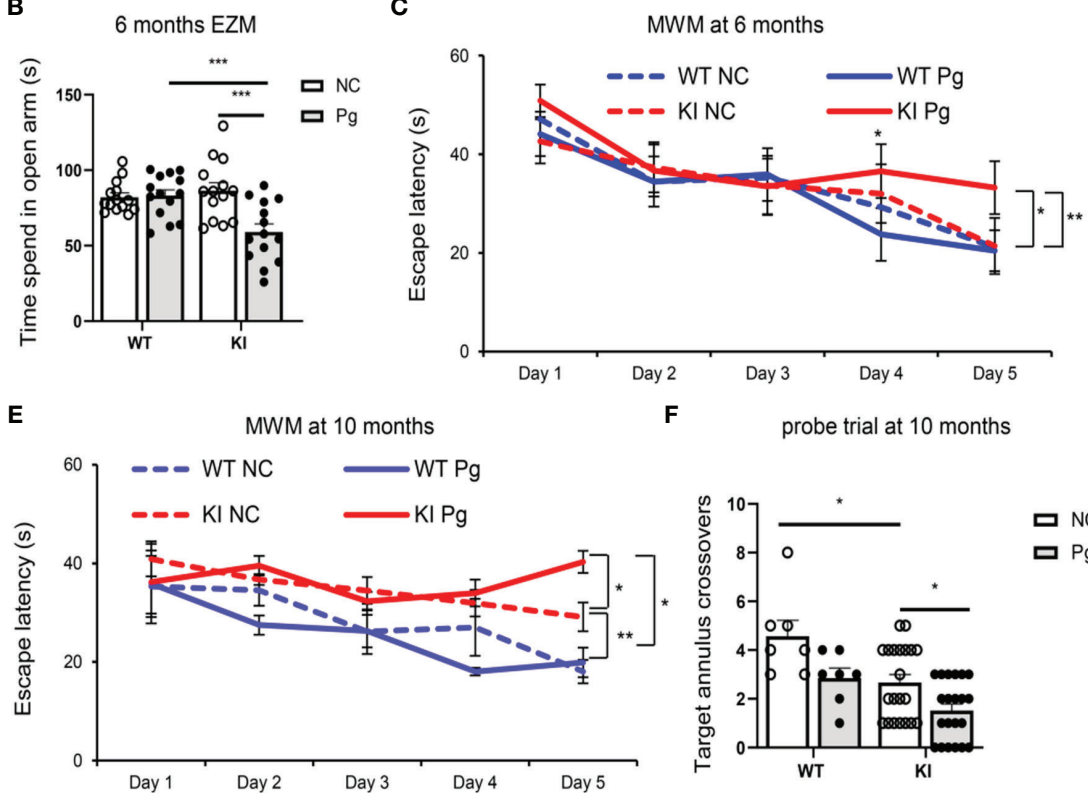

口 NC 口Pg

FIGURE 2 | Pg infection worsens cognitive and behavior impairment in App KI mice. (A) Total distance traveled in open field (OF) tests at 6 months of age. cm, centimeter. (B) Time spent in open arm in elevated zero maze (EZM) tests at 6 months of age. s, second. (C, E) Escape latency in Morris water maze (MWM) tests at 6 (C) and $10(\mathbf{E})$ months of age. (D, F) Target annulus crossovers in probe trial tests at 6 (D) and 10 (F) months of age. A-D, n=14/group; E-F, n=21/ group (App KI mice), $\mathrm{n}=7$ /group (WT mice). Data are expressed as mean \pm SEM. ${ }^{*} P<0.05,{ }^{* *} P<0.01,{ }^{* \star *} P<0.001,{ }^{* \star * *} P<0.0001$ by two-way ANOVA followed with Tukey correction. 


\section{Pg Infection Exacerbates Brain A $\beta$ Production and Amyloid Plaque Deposition in AD Mice}

The development of amyloid plaque, composed mainly of the peptide $\mathrm{A} \beta$, is a pathological hallmark of $\mathrm{AD}(40)$. We next questioned how Pg infection influences brain $A \beta$ accumulation and amyloid plaque deposition in App KI mice. At 4 months of age, accumulation of soluble and insoluble hA $\beta 42$ peptide was noted in the brains of App KI mice, and Pg infection significantly increased the accumulation of soluble hA $\beta 42$ in the hippocampus of App KI mice (Figure 3A). Time-dependent accumulation of hA $\beta 42$ in the brains of non-infected $A p p$ KI mice was seen at 6 and 10 months of age (Figures 3B-E), compared to the level at 4 months. In addition, Pg infection further enhanced hA $\beta$ accumulation in App KI mice at 6 and 10 months of age. Consistently, immunohistochemical analysis of brain sections demonstrated significantly increased amyloid plaque deposition in non-infected App KI mice at 10 months of age compared to 6 months of age, as measured by the number of plaques, the average size of plaques, and the total area occupied by the plaques in hippocampus and cortex (Figures 3F-H). Furthermore, Pg infection significantly increased amyloid plaque deposition in App KI mice at 6 and 10 months of age.

\section{Pg Invades the Brain and Potentiates Neuroinflammation and Complement Activation in AD Mice}

Recent studies have shown that the number of Pg, and its LPS and gingipains, were significantly higher in the autopsied brain tissues of $\mathrm{AD}$ patients than in non-demented controls $(10,11)$, suggesting that Pg can pass the blood-brain barrier (BBB). To verify Pg brain invasion following oral gavage infection, we first assessed the presence of the $h m u Y$ gene, a highly specific gene essential for Pg survival and virulence (33), in the brains of WT and App KI mice. While non-infected WT and App KI controls were negative for the $h m u Y$ gene, both Pg-infected WT and App KI brains were positive for this gene (Figure 4A). We next analyzed the presence of Pg $16 \mathrm{~S}$ rRNA. Both WT and App KI brains showed significantly increased expression of Pg 16S rRNA following Pg infection (Figure 4B). Noteworthy, a significantly higher level of Pg 16S rRNA was detected in the brain tissues from App KI mice as compared to those from WT mice following Pg infection. The presence of Pg in the brain tissues

A

B

C

D
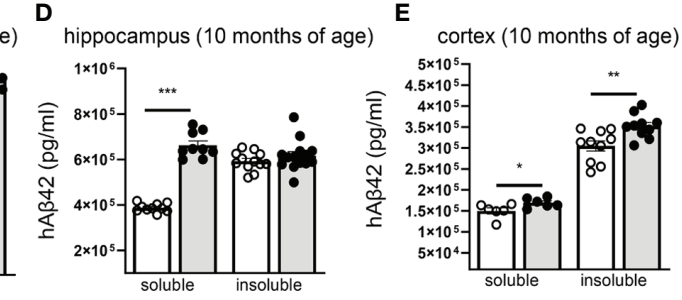

$\mathbf{F}$
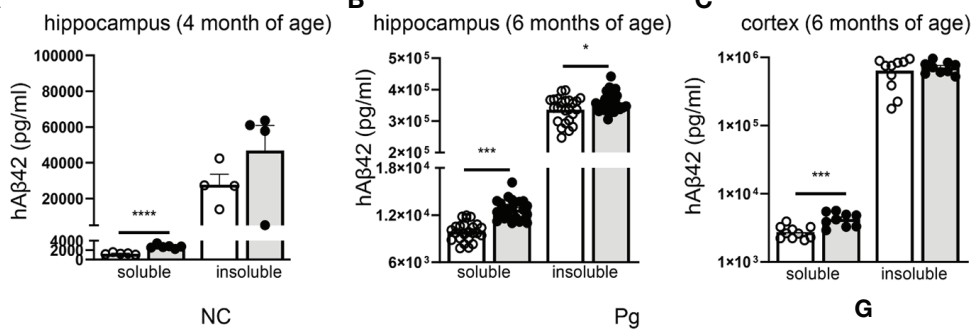

$\mathrm{Pg}$

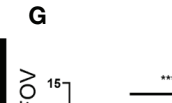

hippocampus
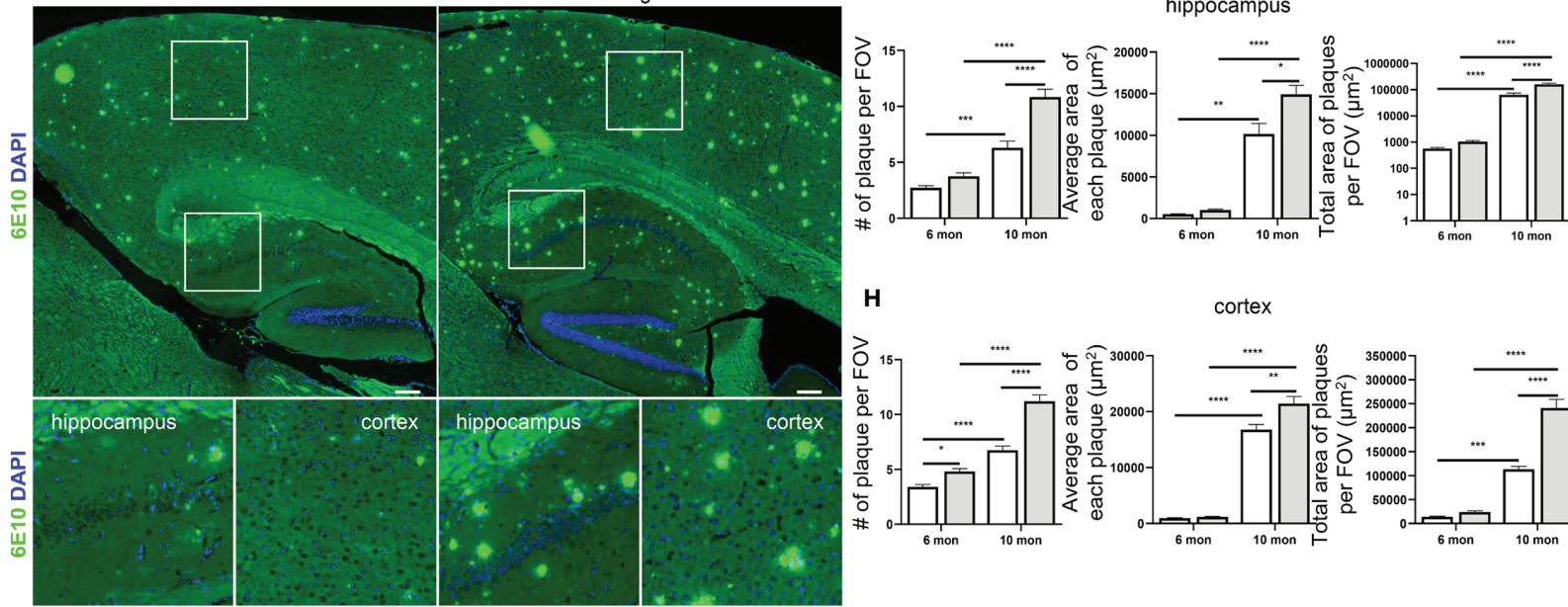

ㅁ KINC

H
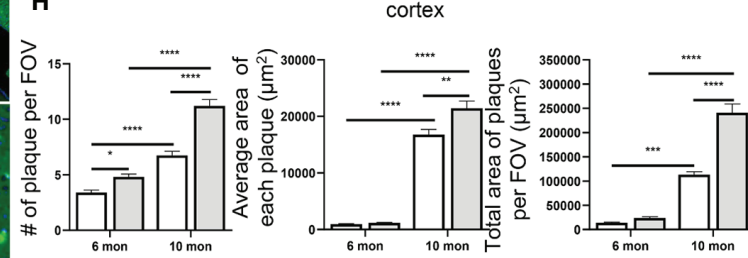

마 $\mathrm{KI} \mathrm{Pg}$

FIGURE 3 | Pg infection accelerates A $\beta$ production and plaque formation in App KI mice. (A-E) Levels of soluble and insoluble hAß42 in the brains of control and Pg-infected App KI mice at 4, 6 and 10 months of age. A, n=4-6/group; B, n=24/group; C-E, n=6-10/group. Samples were run in duplicate in ELISA. (F) Representative micrographs showing $A \beta$ plaques formation in App KI mice at 10 months of age. Whole brain images were stitched with 30 series micrographs captured at $10 \mathrm{x}$ objective using a KEYENCE BZ-800 microscope. Boxed areas were further enlarged. A $\beta$ plaques were labeled with 6E10 (green) and cell nuclei were labeled with DAPI (blue). (G, H) Quantification of the number of A $\beta$ plaques, average plaque size, and total plaque-occupied area per field of view (FOV) in the hippocampus (G) and cortex (H) of App KI mice at 6 and 10 months of age. Five representative regions of the cortex and hippocampus were captured at 40x objective from each brain section and quantified (n=5-7/group). Data are expressed as mean \pm SEM. ${ }^{\star} P<0.05$, ${ }^{\star *} P<0.01$, ${ }^{\star \star \star} P<0.001$, ${ }^{\star \star \star \star} P<0.0001$ by unpaired Student $t$-test $(\mathbf{A}-\mathbf{E})$, or by two-way ANOVA followed with Tukey correction $(\mathbf{G}, \mathbf{H})$. 


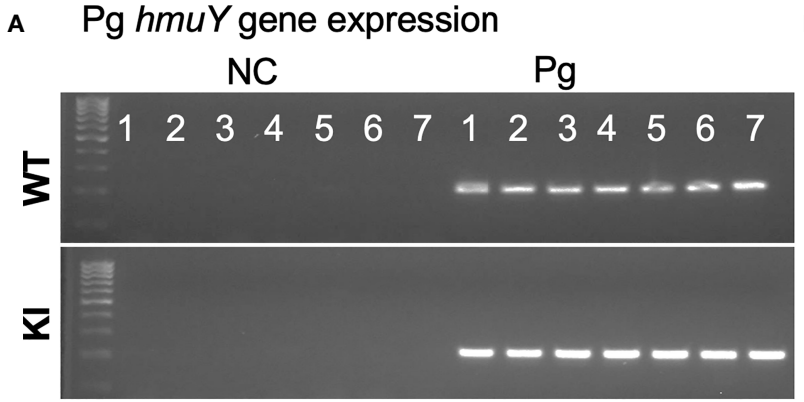

C

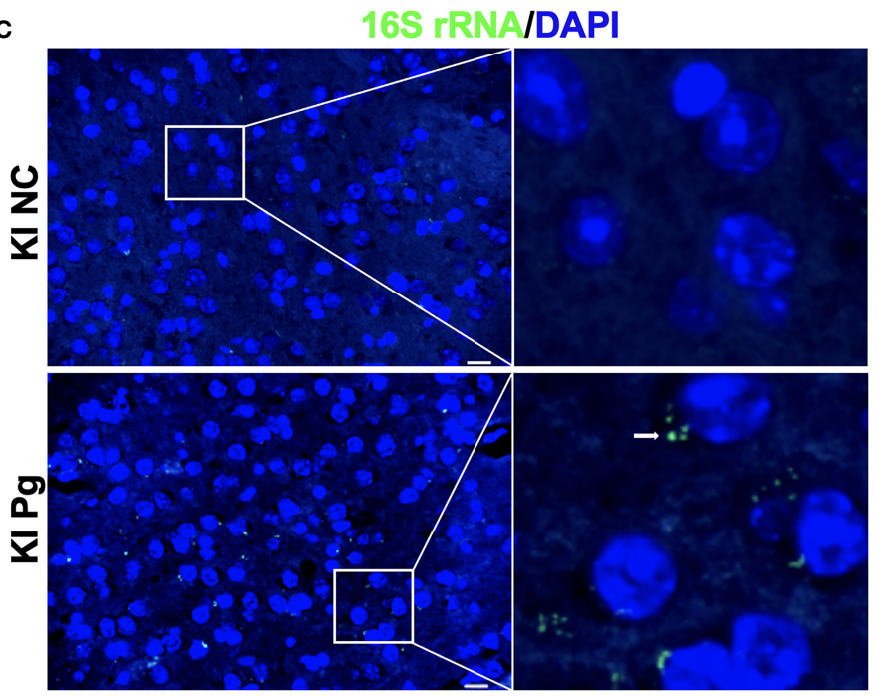

$\mathbf{E}$

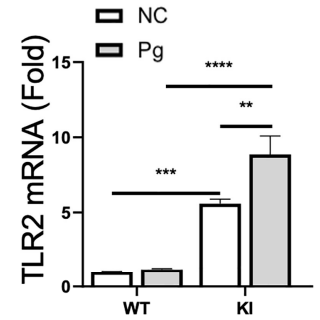

$\mathbf{F}$

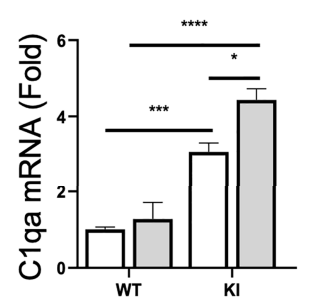

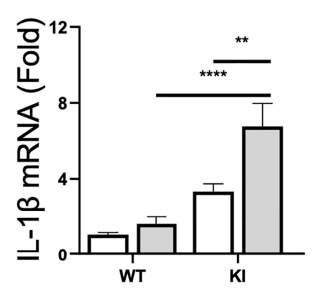

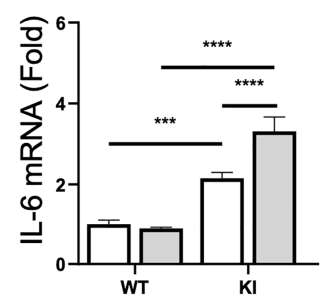

G

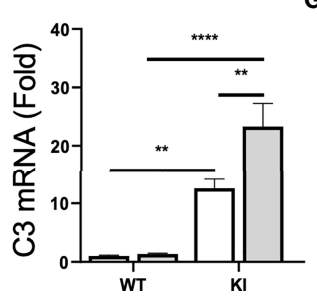

B

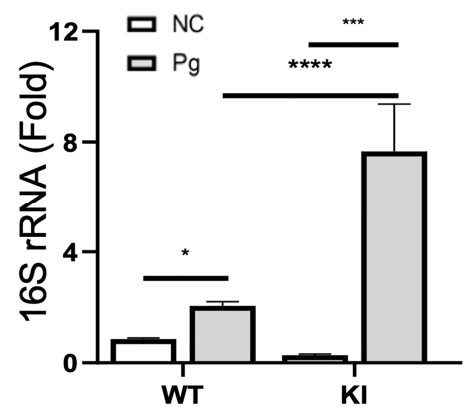

D
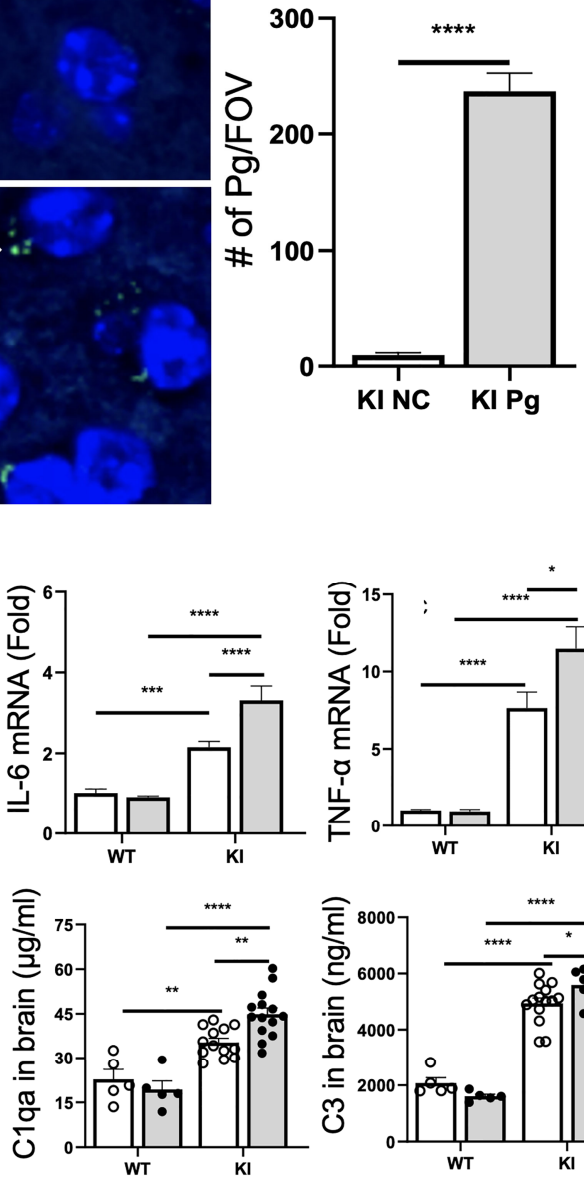
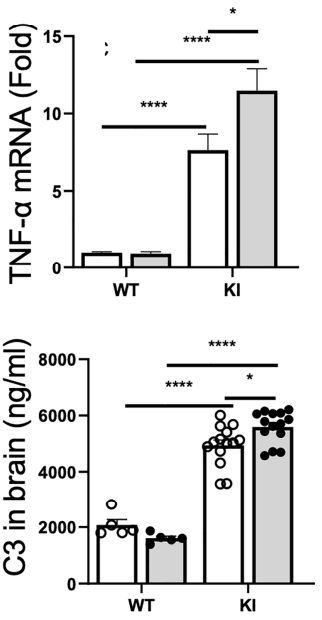

FIGURE 4 | Pg invades the brain and induces neuroinflammation and complement activation. (A) Pg-specific $h$ muY gene expression in brains from WT and App KI mice. (B) Pg-specific $16 \mathrm{~S}$ rRNA expression in brains from WT and App KI mice. The levels of gene expression were normalized to GAPDH and shown as fold changes. Samples were run in duplicates ( $n=7 /$ group). (C) Representative micrographs depicting intracellular localization of Pg in the cortex of brains from App Kl mice. Pg were probed with 16S rRNA with FITC (green, arrowhead) and nuclei were labeled with DAPI (blue). Boxed areas were further enlarged. Scale bar, $10 \mu \mathrm{m}$. (D) Quantification of $\mathrm{Pg}$ in brain sections from non-infected and Pg-infected App KI mice. Five representative regions were captured at $40 \times$ objective from each brain section and quantified ( $n=5-7 /$ group); FOV, field of view. (E) The relative gene expression of inflammatory cytokines and TLR2 in brain tissues from WT and App KI mice. Samples were done in duplicates ( $n=5-7 /$ group). (F) The relative gene expression of C1qa and $\mathrm{C} 3$ in brain tissues from WT and App KI mice. Samples were

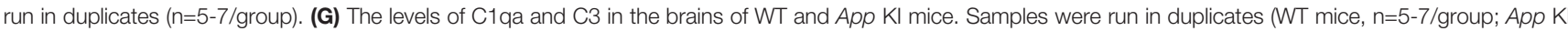
mice, $n=10-12$ /group). Data are expressed as mean \pm SEM; ${ }^{\star} P<0.05,{ }^{\star \star} P<0.01,{ }^{\star \star \star} P<0.001,{ }^{\star \star \star \star} P<0.0001$ by two-way ANOVA followed with Tukey correction (B, E-G) or by unpaired Student $t$-test (D). 
of Pg-infected App KI mice was further ascertained by FISH using Pg specific 16S rRNA probe. Hybridization of the $16 \mathrm{~S}$ rRNA probe to bacterial aggregates was located at the perinuclear regions of brain cells in Pg-infected App KI mice (Figures 4C, D). No Pg 16S rRNA was detected in non-infected App KI mice brains. These results demonstrate that upon the establishment of periodontal infection, Pg can access the brain and that $\mathrm{AD}$ mice are more susceptible to Pg brain invasion than WT mice.

Neuroinflammation is a critical component of neurodegenerative diseases like AD (41). Thus, we next determined how oral Pg infection affected the neuroinflammatory status of experimental mice. Without Pg infection, App KI mice showed significantly higher levels of TLR2 and inflammatory cytokine gene expression than WT mice (Figure 4E). Pg infection further enhanced the expression of these genes in the brains of App KI mice, while a minimal inflammatory response was observed in WT mice following Pg infection. Similar results were seen with $\mathrm{C} 1 \mathrm{qa}$ and $\mathrm{C} 3$ gene and protein expression in the brains of WT and App KI mice. Noninfected $A p p$ KI mice showed significantly higher levels of brain $\mathrm{C} 1 \mathrm{qa}$ and $\mathrm{C} 3$ gene and protein expression than WT mice, and Pg infection further enhanced their expression in the brains of App KI mice (Figures 4F, G). However, minimal C1qa and C3 response was noted in the brains of WT mice following Pg infection. These results suggest that periodontal infection contribute significantly to the neuroinflammatory milieu established by AD possibly via activation of complement system.

\section{Pg Infection Enhances Microglia Activation and Their Colocalization With C1q in App KI Mice}

As the major immune cells in the CNS, microglia activation is an invariable feature of $\mathrm{AD}$ pathology, and activated microglia represent a major source of inflammatory factors in $\mathrm{AD}(42)$. We next assessed the activation of microglia and the spatial association between microglia and $\mathrm{Clq}$ in App KI mice. Pg infection significantly increased the number of $\mathrm{IBA}^{+}$ microglia in App KI mice (Figures 5A-C). In addition, a significant increase in the number of $\mathrm{Clqa}^{+} \mathrm{IBA}^{+}$cells was observed in Pg-infected App KI mice.

\section{Pg Amplifies A $\beta$-Primed Microglia Activation via C1q}

Given that AD mice exhibited neuroinflammation without Pg infection, and that Pg entered the brains of WT mice but induced minimal neuroinflammation compared to $\mathrm{AD}$ mice, we questioned if a potential interplay between Pg and $A \beta$ could result in the increased neuroinflammation observed in $\mathrm{AD}$ mice. Primary microglia were cultured with different concentrations of $A \beta o, P g, A \beta o$ together with Pg, or pre-treated with $A \beta o$ followed by Pg infection. Interestingly, while $A \beta o$ alone at various doses induced very low levels of inflammatory cytokine and complement gene expression in microglia (Figures 6A, B), costimulation of microglia with $\mathrm{A} \beta \mathrm{O}$ and $\mathrm{Pg}$ at the same time decreased the gene expression of inflammatory cytokines as compared to Pg stimulation alone (Figure 6A). However, pre-
A

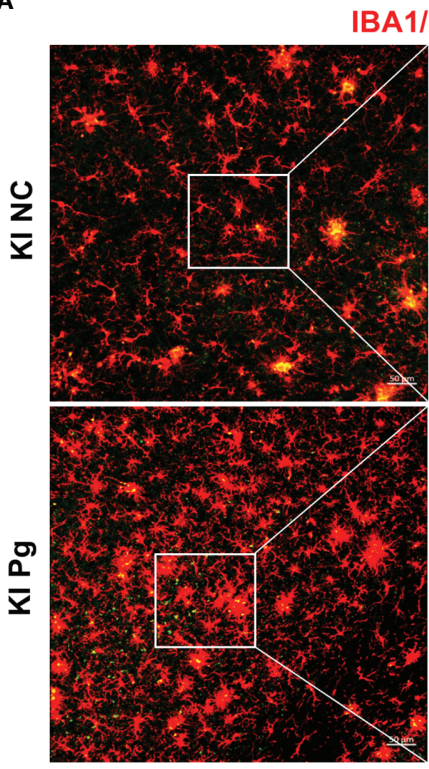

BA1/C1qa

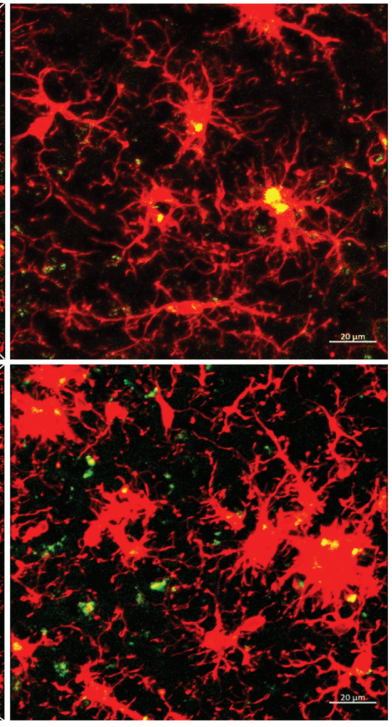

B

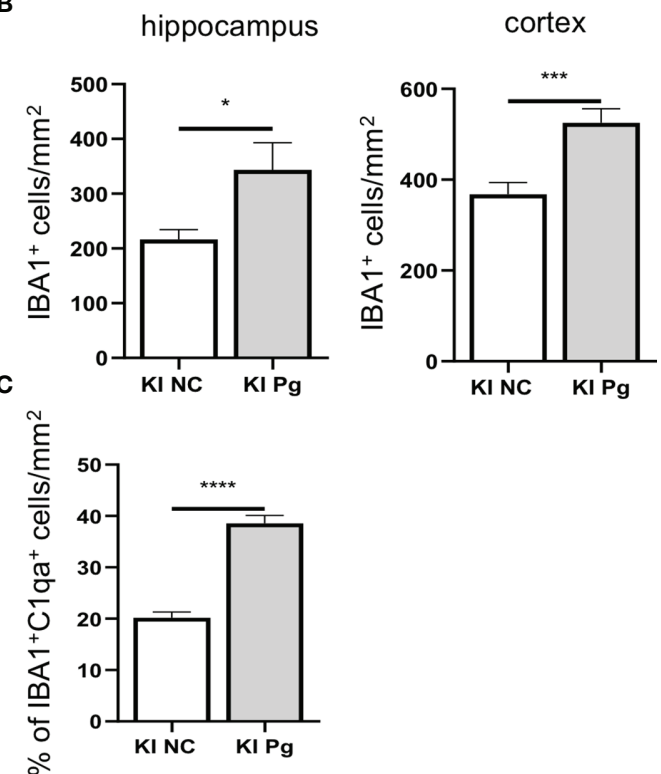

FIGURE 5 | Pg activates microglia in App KI mice and co-localize with complement C1q. Brain sections from 6-month-old non-infected and Pg-infected App KI mice were immune-stained with antibodies against IBA1and C1qa. (A) Representative Z-stack images of brain sections depicting the spatial association between microglia (red) and C1qa (green). (B) Quantification of IBA $1^{+}$cells in the hippocampus and cortex regions. $\mathrm{n}=6-7$ mice/group. (C) Percentage of IBA1 ${ }^{+} \mathrm{C} 1$ qa ${ }^{+}$ microglia in non-infected and $\mathrm{Pg}$-infected $\mathrm{App} \mathrm{KI}$ mice. Five representative micrographs of the cortex and hippocampus regions from each mouse were analyzed ( $\mathrm{n}=5$-7 mice/group). Data are expressed as mean \pm SEM. ${ }^{\star} P<0.05,{ }^{\star \star \star} P<0.001,{ }^{\star \star \star \star} P<0.0001$ by unpaired Students $t$-test. 
A

B
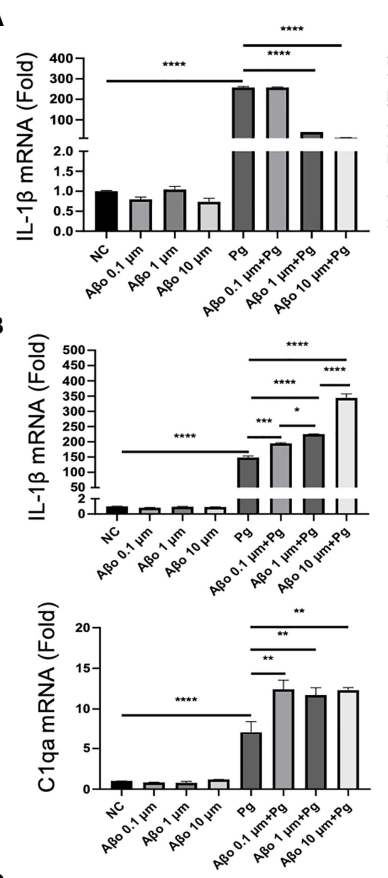
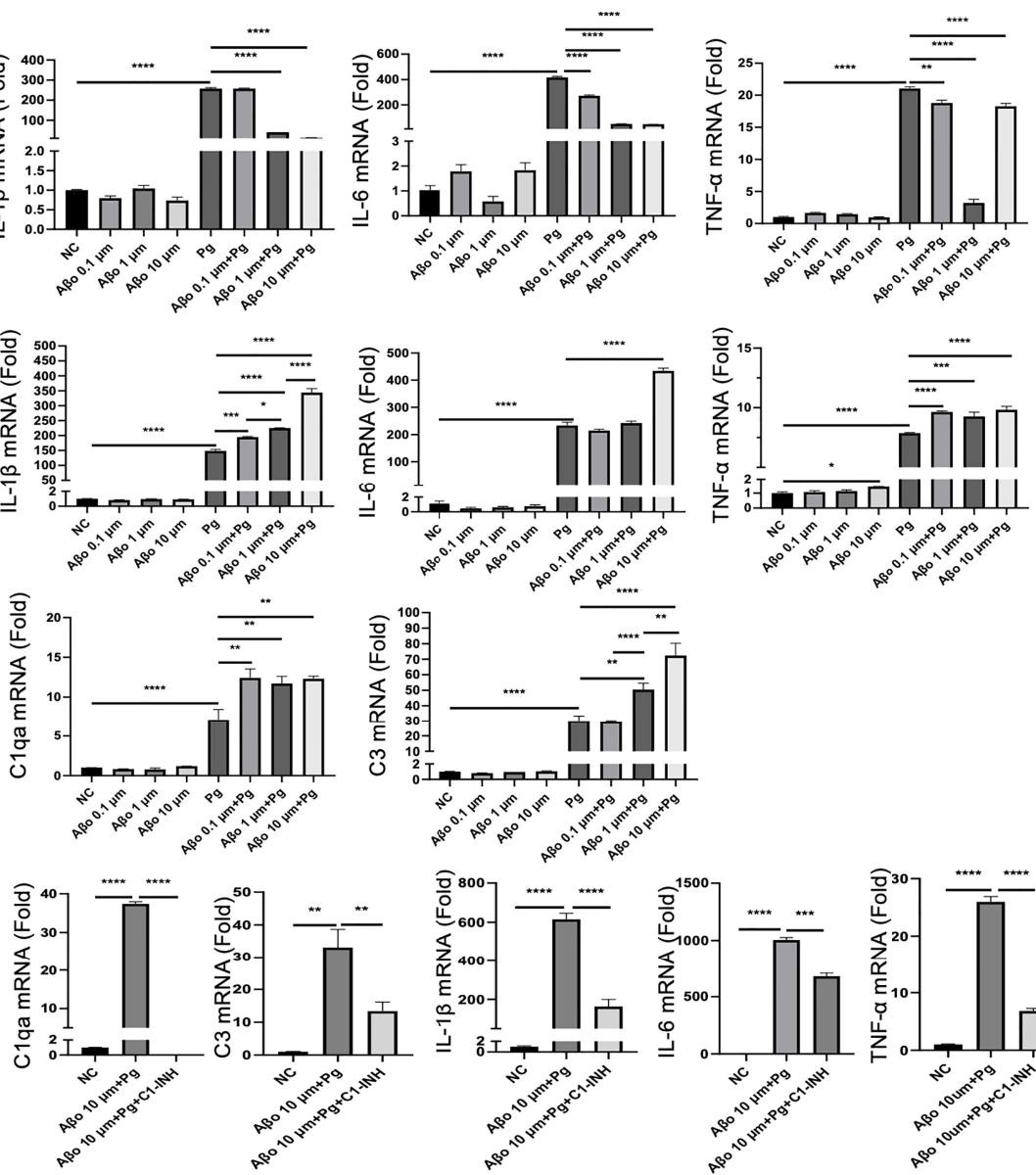

D
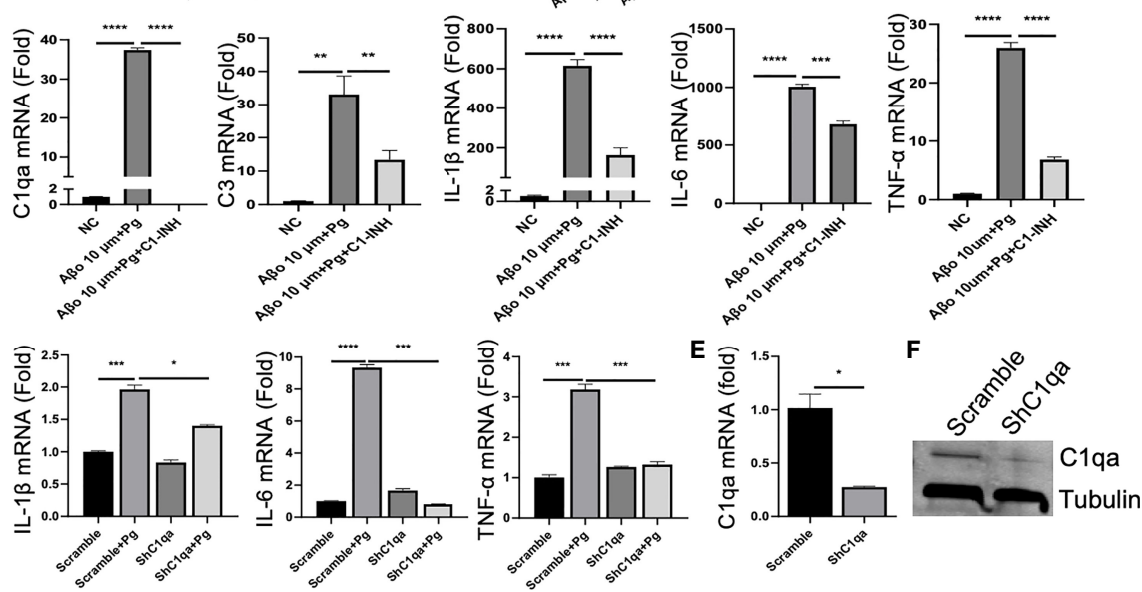

FIGURE 6 | Effect of Aßo and complement activation on Pg-induced microglial inflammatory responses. (A, B) Aßo on Pg-induced cytokine production and complement activation. Primary microglia were treated with $\mathrm{A} \beta \mathrm{o}(0.1,1$ or $10 \mu \mathrm{M}), \mathrm{Pg}(\mathrm{MOl}=50)$, or co-stimulated with $\mathrm{A} \beta \mathrm{o}$ and $\mathrm{Pg}$ for $24 \mathrm{~h}(\mathbf{A})$, or pretreated with Aßo for $6 \mathrm{~h}$ followed by Pg stimulation for $24 \mathrm{~h}$ (B). Relative gene expression of IL-1 $\beta$, IL-6, TNF- $\alpha$, C1qa, and C3 was analyzed by RT-qPCR. (C) C1 inhibition on $\mathrm{Pg}$-induced inflammatory gene expression by microglia. Primary microglia were untreated or pretreated with $\mathrm{C} 1-\mathrm{INH}$ for $4 \mathrm{~h}$, and then treated with $\mathrm{A} \beta \mathrm{o}$ (10 $\mu \mathrm{M})$ for 6 h followed by $\mathrm{Pg}(\mathrm{MOl}=50)$ for 24 h. Relative gene expression of C1qa, C3, IL-1ß, IL-6, and TNF- $\alpha$ in microglia were analyzed by RT-PCR. (D) Effect of C1qa depletion on Pg-induced cytokine gene expression by microglia. Primary microglia cells expressing scramble or $\mathrm{C} 1$ qa shRNA vectors were treated with Pg (MOl=50) for 24 h. Relative gene expression of IL-1 $\beta, \mathrm{IL}-6$, TNF- $\alpha$ in microglia were analyzed by RT-PCR. Expression of C1qa mRNA (E) and protein (F) in primary microglia verified by RT-PCR and Western blot. Samples were run in duplicates. Data are expressed as mean \pm SEM of three independent experiments; ${ }^{\star} P<0.05$, ${ }^{\star \star} P<0.01$, ${ }^{\star \star \star} P<0.001,{ }^{\star \star \star \star} P<0.0001$ by one-way ANOVA followed with Tukey correction.

treatment of microglia with $\mathrm{A} \beta$ o significantly potentiated Pginduced inflammatory cytokine and complement gene expression (Figure 6B).

To assess if the increased inflammatory response by Pg in A $\beta$ primed microglia was mediated by complement activation, microglia were pre-treated with $\mathrm{C} 1-\mathrm{INH}$, a protease inhibitor of the classical complement component C1 (43), followed by $\mathrm{A} \beta \mathrm{o}$ and then Pg stimulation. Our results showed that C1-INH significantly decreased Pg-induced complement activation and cytokine production in $\mathrm{A} \beta$-primed microglia (Figures 6C, D). To further verify if $\mathrm{Clq}$ spurs neuroinflammation in the presence of $\mathrm{Pg}$, primary microglia were transfected with shC1qa or scramble vectors and then treated with Pg. Knock-down of C1qa significantly reduced Pg-induced inflammatory cytokine gene expression in microglia (Figures 6D-F). These results suggest that $\mathrm{Clq}$ plays a critical role in the amplification of microglia activation and neuroinflammation in $\mathrm{AD}$ mice following Pg infection. 


\section{Pg Infection Exacerbates Synapse Loss and the Colocalization of C1q With Synaptic Puncta in App KI Mice}

One of the prominent pathological features of AD is the early loss of synapses (44). In addition, studies have shown that progressive brain $\mathrm{C} 1 \mathrm{q}$ accumulation is associated with cognitive decline and memory impairment in aging, via microglia engulfment of the C1q-tagged synapses (45). Given the significantly increased brain $\mathrm{C} 1 \mathrm{q}$ expression and remarkable memory deficits in App KI mice following Pg infection, we evaluated if synapses were altered as a result of periodontal infection, and its correlation with C1q expression. A significant loss of pre- and postsynaptic puncta (marked by SNAP25 and PSD95, respectively), as well as the colocalization of pre- and postsynaptic puncta, in the hippocampus and cortex of noninfected App KI mice were seen at 10 months of age compared to 6 months of age (Figures 7A-D). In addition, Pg infection significantly increased the loss of synaptic puncta in App KI mice at 6 and 10 months of age than their respective noninfected controls. Furthermore, a significant increase in the numbers of C1qa-labeled PSD95 puncta in the hippocampus and cortex was observed in non-infected and Pg-infected App KI
A
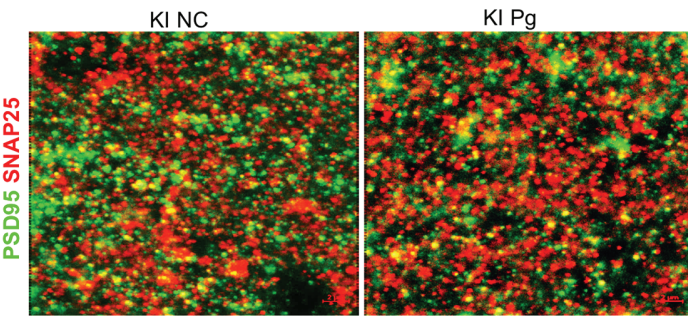

C

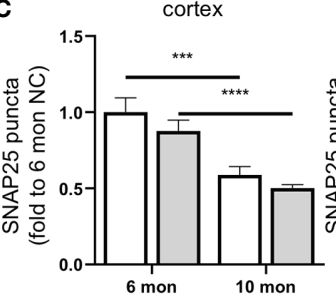

E
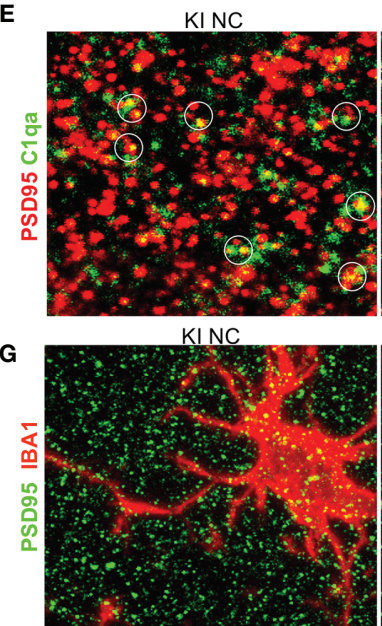
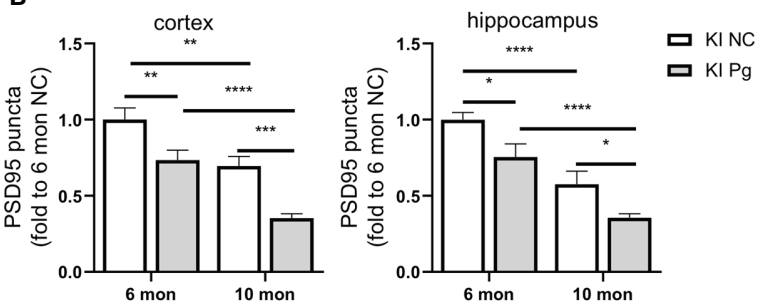

D
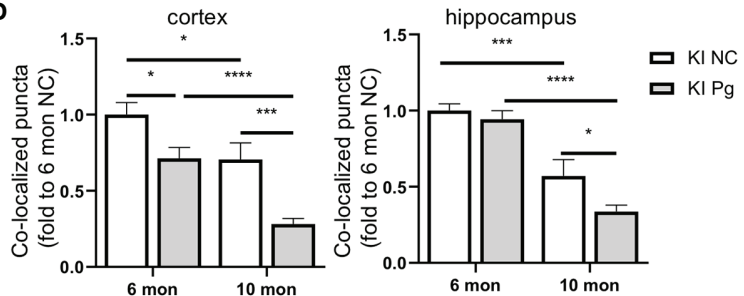

F
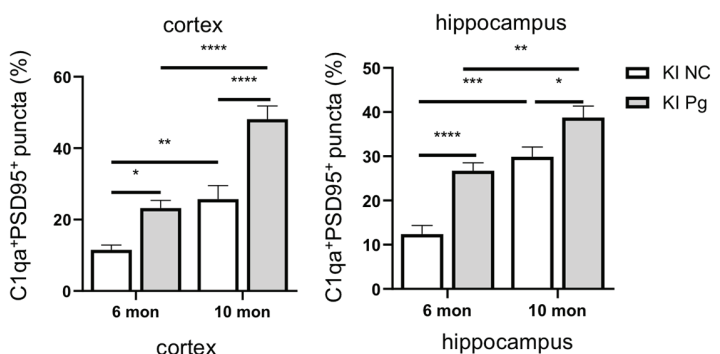

hippocampus
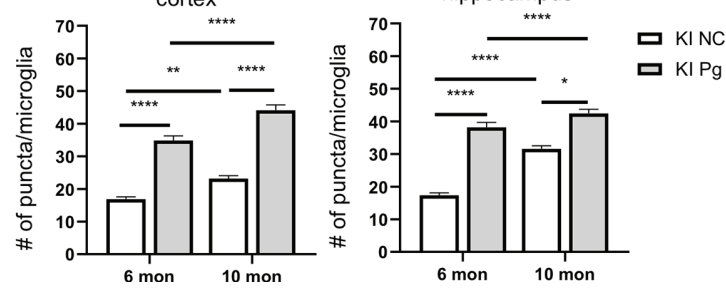

FIGURE 7 | Pg infection enhances microglial elimination of synapses in App KI mice. (A) Representative high magnification Z-stack images showing SNAP 25 (presynaptic marker, red) and PSD95 (postsynaptic marker, green) synaptic terminals in the cortex and hippocampus from non-infected and Pg-infected App KI mice at 10 months of age. (B-D) Quantification of PSD95 puncta (B), SNAP25 puncta (C), and the co-localized PSD95 and SNAP25 puncta (D) in the cortex and hippocampus CA1 regions from non-infected and Pg-infected App KI mice at 6 and 10 months of age. Scale bar: $2 \mu \mathrm{m}$. (E) Representative high magnification Zstack images of C1qa (green) and PSD95 (red) co-stained puncta in the cortex and hippocampus of the brains from non-infected and Pg-infected App KI mice at 10 months of age. Circles show examples of C1qa puncta co-localized with PSD95 puncta. Scale bar: 4 um. (F) Quantification of co-stained C1qa and PSD95 in the cortex and hippocampus CA1 regions from non-infected and Pg-infected App KI mice at 6 and 10 months of age. (G) Representative high magnification Z-stack images of subicular microglia (IBA $1^{+}$, red) co-stained with PSD95 (green) from non-infected and Pg-infected App KI mice at the 10 months of age, displaying elimination of synapses by microglia. Scale bar, $5 \mu \mathrm{m}$. (H) Quantification of engulfed PSD95 puncta density in microglia in the cortex and hippocampus CA1 regions of the brains from non-infected and Pg-infected App KI mice at 6 and 10 months of age. Data are expressed as mean $\pm \mathrm{SEM}(\mathrm{n}=4-7 \mathrm{mice} / \mathrm{group})$. ${ }^{\star} P<0.05$, ${ }^{\star \star} P<0.01,{ }^{\star \star \star} P<0.001,{ }^{\star \star \star \star} P<0.0001$ by two-way ANOVA followed with Tukey correction. 
mice at 10 months of age compared to that at 6 months of age, and Pg-infected App KI mice showed a significantly higher number of $\mathrm{C} \mathrm{qa}^{+} \mathrm{PSD} 95^{+}$puncta than their non-infected controls at 6 months and 10 months of age (Figures 7E, F). Moreover, significant increase numbers of PSD95 puncta within microglial cell bodies was observed in the cortex and hippocampus of App KI mice at 10 months of age compared to those at 6 months of age, and $\mathrm{Pg}$ infection significantly increased the numbers at 6 and 10 months of age (Figures 7G, $\mathbf{H})$. These results suggest that $\mathrm{C} 1 \mathrm{q}$ and microglia communicate to regulate synapse pruning, and that periodontal infection potentiates C1q-mediated synapse engulfment by microglia.

\section{Blocking C1qa Reduces Pg Induced Microglia-Mediated Synapse Loss In Vitro}

To further confirm if the increased synapse removal by microglia in the presence of $\mathrm{Pg}$ was $\mathrm{C} 1 \mathrm{q}$ dependent, primary microglia expressing C1qa shRNA or scramble vectors were co-cultured with primary neurons in the presence or absence of $\mathrm{Pg}$, and the expression of PSD95 puncta in the co-cultures were analyzed. With scramble shRNA expression, PSD95 density in the cocultures was reduced by $\sim 50 \%$ following $\mathrm{Pg}$ stimulation (Figures 8A, B), demonstrating that $\mathrm{Pg}$ infection enhances the loss of synapses. However, with shClqa expression, no significant loss of PSD95 was seen following Pg stimulation. Importantly, the number of PSD95 puncta in Pg-treated cocultures with shC1qa expression was significantly higher than that in Pg-treated co-cultures with scramble shRNA expression, indicating that depletion of C1qa in microglia prevents $\mathrm{Pg}$ induced synapse loss. We next verified the presence of PSD95 puncta within microglia in the co-cultures. Increased number of PSD95 puncta were observed within microglia expressing scramble vectors after Pg stimulation (Figures 8A, C). However, no increase in PSD95 puncta within microglia expressing shC1qa was seen following $\mathrm{Pg}$ stimulation. To further confirm these results, microglia cells were sorted out from the co-cultures by FACS. Pg infection led to an increased level of PSD95 expression in the microglial cell lysates from the co-cultures with scramble shRNA expression in microglia (Figure 8D). However, no increase in PSD95 expression was seen in the microglial cell lysates from the co-cultures with shC1qa expression. No NeuN (neuronal cell marker) signal was detected in any of the microglial cell lysates, indicating that there was no contamination of neurons in the sorted microglia and that the observed PSD95 intensity was due to microglial engulfment of neuronal synapses. Taken together, these results indicate that $\mathrm{C} 1 \mathrm{q}$ expression in microglia is necessary for Pg-induced enhancement of synapse engulfment by microglia.

\section{DISCUSSION}

Increasing evidence suggests that periodontitis is associated with and may contributes to the development of $\mathrm{AD}$. However, the

A
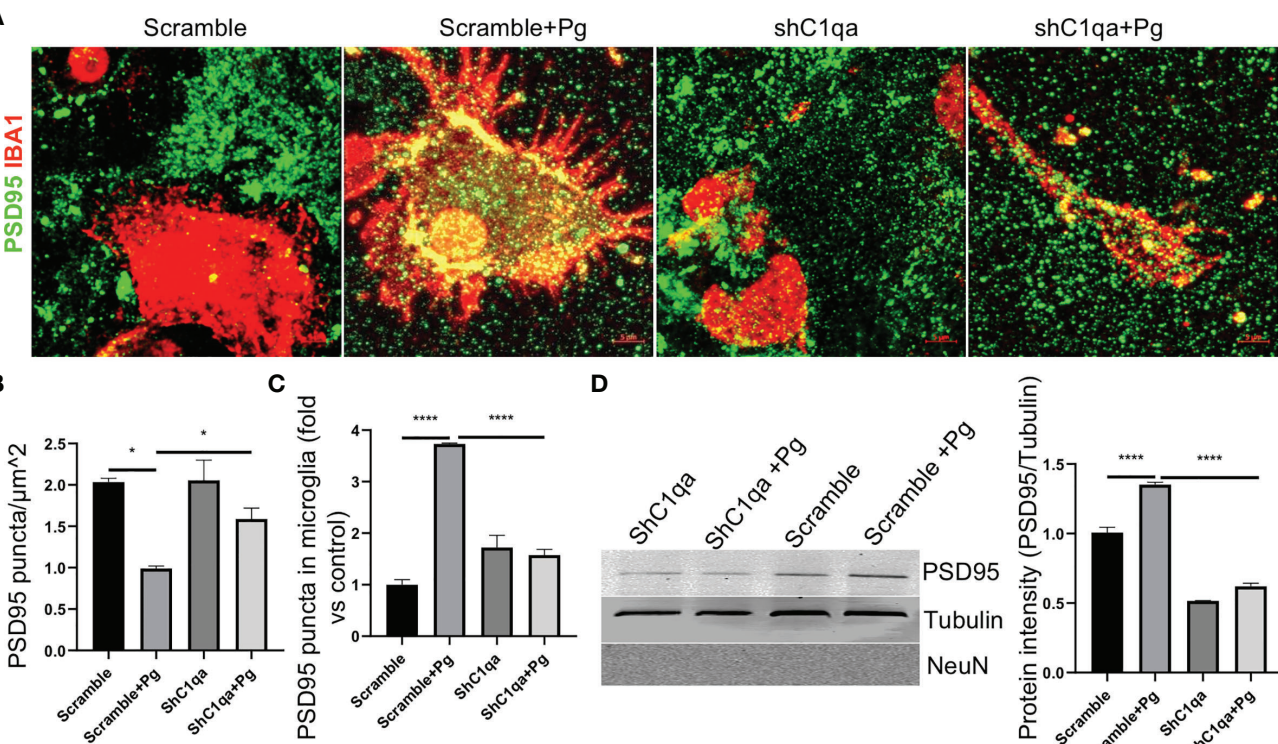

D
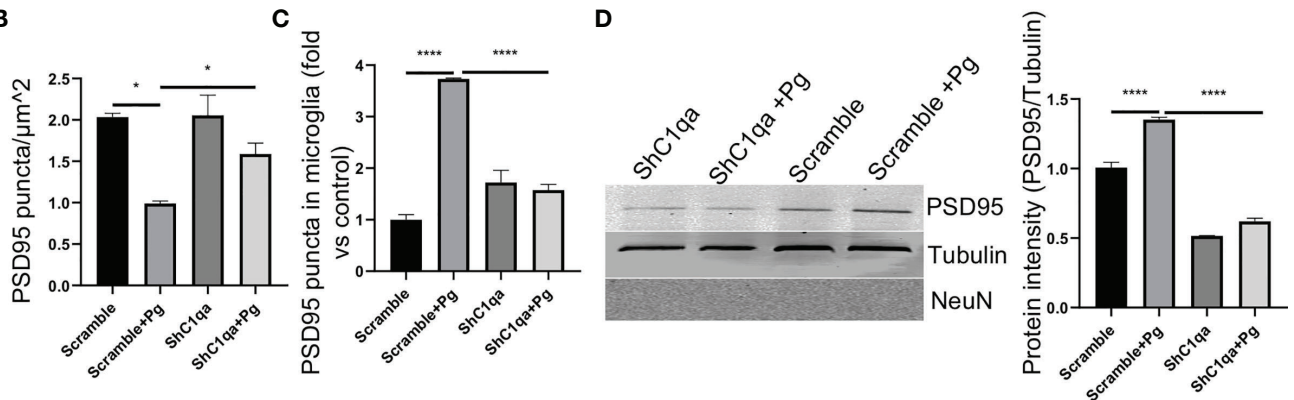

FIGURE 8 | Depletion of C1qa prevents Pg-induced synapse loss by microglia in vitro. (A) Representative Z-stack images of neuro-microglia (expressing shC1q or scramble vector) co-cultures in the presence or absence of $\mathrm{Pg}$ (MOI=50). Cultures were stained with IBA1 (red) and PSD95 (green). Scale bar: $5 \mu \mathrm{m}$. (B, C) Quantification of PSD95 puncta in the co-cultures (B) and in microglial cell bodies (C). (D) Western blot analysis of PSD95 puncta in FACS-sorted IBA1 ${ }^{+}$microglia lysates from the cocultures. NeuN, neuronal marker. Densitometric analysis was performed using ImageJ software, and normalized to tubulin and expressed as fold changes over scramble control. Data are expressed as mean \pm SEM of three independent experiments. ${ }^{\star} P<0.05,{ }^{\star \star \star \star} P<0.0001$ by one-way ANOVA followed with Tukey correction. 
mechanisms underlying such association have not yet been delineated. In the present study, we provide new evidence that the neuroinflamamtory staus established by $\mathrm{AD}$, is greatly complicated by periodontal infection and the consequential entry of $\mathrm{Pg}$ into the brain via $\mathrm{A} \beta$-primed microglial activation, thus unquestionably and significantly aggravating $\mathrm{AD}$, and that Pg-induced brain overactivation of complement $\mathrm{Clq}$ is critical for periodontitis-associated acceleration of $\mathrm{AD}$ progression by amplifying microglial activation, neuroinflammation, and tagging synapses for microglial engulfment.

Periodontitis-related bacteremia, as well as the migration of Pg from gingival tissues to distant tissues via intravascular dissemination, has been reported in animal and human studies $(46,47)$. In addition, periodontitis may induce a systemic inflammatory state through mechanisms that include dissemination of pro-inflammatory cytokines (6). In this study, we were able to detect the presence of Pg in the brains of WT and $\mathrm{AD}$ mice following $\mathrm{Pg}$ infection. Importantly, a significantly higher amount of $\mathrm{Pg}$ were detected in the brains of $\mathrm{AD}$ mice than WT mice. One reason for the increased vulnerability of AD mice to Pg invasion of the brain may due to the increased $\mathrm{BBB}$ permeability related to increased activation of the innate immune response in the brains of $\mathrm{AD}$ mice, thus allowing for easier translocation of pathogens through the barrier (48). Along this line, we observed a pre-existing pro-inflammatory cytokine response in the brains of AD mice without Pg infection, and $\mathrm{Pg}$ infection further enhanced the neuroinflammation in $\mathrm{AD}$ mice.

Microglia are belived to be the main source of $\mathrm{Clq}$ in the brain (49), consistent with this notion, we found that Pg infection significantly increased the colocalization of $\mathrm{Clq}$ with microglia, and $\mathrm{Clq}$ plays an important role in Pg-induced inflammation in microglia. Previous studies have reported that the complement system is hyper-activated in the brain tissues from $\mathrm{AD}$ patients and mouse models $(18,19)$, inhibition or lack of complement components could ameliorate $\mathrm{AD}$-relevant characters in multiple mouse models of $\mathrm{AD}(18,50,51)$. In addition, absence of $\mathrm{Clq}$ leads to less neuropathology in $\mathrm{AD}$ mice. On the other hand, activated complement fragments were abundant in the gingival crevicular fluids (GCF) and the chronically inflamed gingiva from patients with periodontitis, but were either undetectable or present in very low levels in the GCF and gingiva of healthy control individuals (52). Periodontal treatment that decreased clinical indices of periodontal inflammation has also been shown to decrease complement activity in GCF (53). Moreover, interception of the complement cascade protected mice and non-human primates from periodontitis (54). Thus, a dysregulated complement system may be a driver of chronic, non-resolving neuroinflammation in $\mathrm{AD}$ in the presence of periodontal infection.

Microglia are long-lived tissue-resident macrophages in the CNS (55). Like macorphages, microglia express pattern recognition receptors, e.g., TLRs, and can be activated by multiple exogeous TLR ligands (56). In addition, microglia are believed to possesse innate immune memeory after experiencing a primary "priming" or "desensitizing" stimulus, react with a stronger (immune training) or weaker (immune tolerance) immune response to a subsequent stimulus $(57,58)$. Pg mainly signals through TLR2 to induce periodontal inflammation and bone loss (59). Interestingly, TLR2 is also a primary receptor for $\mathrm{A} \beta$ peptides to trigger neuroinflammation (60). Thus, $A \beta$ accumulation in the brain may underline the pre-existed brain TLR2 activation and neuroinflammation in $\mathrm{AD}$ mice in the absence of $\mathrm{Pg}$ infection. Interestingly, our studies showed that $\mathrm{A} \beta \mathrm{o}$ alone was unable to activate mciroglial cells in vitro. Yet, pretreatment of microglia cells with $\mathrm{A} \beta \mathrm{o}$ followed by $\mathrm{Pg}$ stimulation led to a significant increase in Pg-induced inflammatory response even when a very low amount of $\mathrm{A} \beta \mathrm{o}$ was used, which is consistent with our in vivo findings that $\mathrm{Pg}$ infection amplified compelement activation and neuroinflamamtion in $\mathrm{AD}$ mice. Therefore, it is likely that $\mathrm{A} \beta$ accumulation in $\mathrm{AD}$ mice may serve as a first "hit" to prime or train microglia, while Pg brain invasion as a second "hit" to activate the primed microglia, leading to exaggerated neuroinflamamtion in $\mathrm{AD}$ in the presence of periodontal infection. It is also possible that brain dissemination of $\mathrm{Pg}$ or inflammatory mediators can prime microglia for subsequent $\mathrm{A} \beta$ or inflammatory stimuation (61), which would suggest that periodontitis not only aggravates the severity of $\mathrm{AD}$, but also increases the host susceptibility to AD.

It is important to point out that, in our study, minimal brain complement activation and neuroinflammation were seen in WT mice following Pg infection, despite Pg brain invasion. A possible explanation is that $A \beta$ production in a healthy brain may help sequester the invading pathogens. In this regard, previous studies have shown that $A \beta$ can protect culture cells from microbial infection by forming fibrils that entrap the pathogens and destroy cell membranes (62). In line with these observations, we found that in vitro co-stimulation of microglial cells with $\mathrm{A} \beta \mathrm{o}$ and $\mathrm{Pg}$ at the same time significantly impaired Pg-induced cytokine production.

Emerging research indicates that early and extra synapse loss is a predictor of cognitive impairment and the degree of synapse loss correlates most strongly with cognitive decline in AD (63). Several lines of evidence support the notion that synapse loss in $\mathrm{AD}$ is caused by complement-mediated synaptic pruning by microglia, and that C1q deficiency leads to less synapse loss and neuropathology in $\mathrm{AD}$ mice $(18,51,64)$. Therefore, we reasoned that elevated complement and microglia activation induced by Pg infection would exacerbate synapse loss in AD mice. Indeed, we observed a significant loss of synapses and increased colocalization of $\mathrm{Clq}$ with synapses in $\mathrm{AD}$ mice following $\mathrm{Pg}$ infection. In addition, more synaptic puncta were observed within microglia following Pg infection, and this engulfment was prevented by depleting C1qa. However, how C1q-labeled synapses provide an "eat me" signal to microglia needs to be addressed in future studies. Furthermore, it will also be of interest to see if $\mathrm{C} 1 \mathrm{q}$ inhibition or deficiency in vivo is sufficient to mitigate Pg-mediated acceleration of AD pathology.

In conclusion, we propose a "two-hit" model of periodontitisassociated aggravation of $\mathrm{AD}$ progression, with brain amyloid $\beta$ accumulation as the first "hit", and Pg invasion of the brain as the 


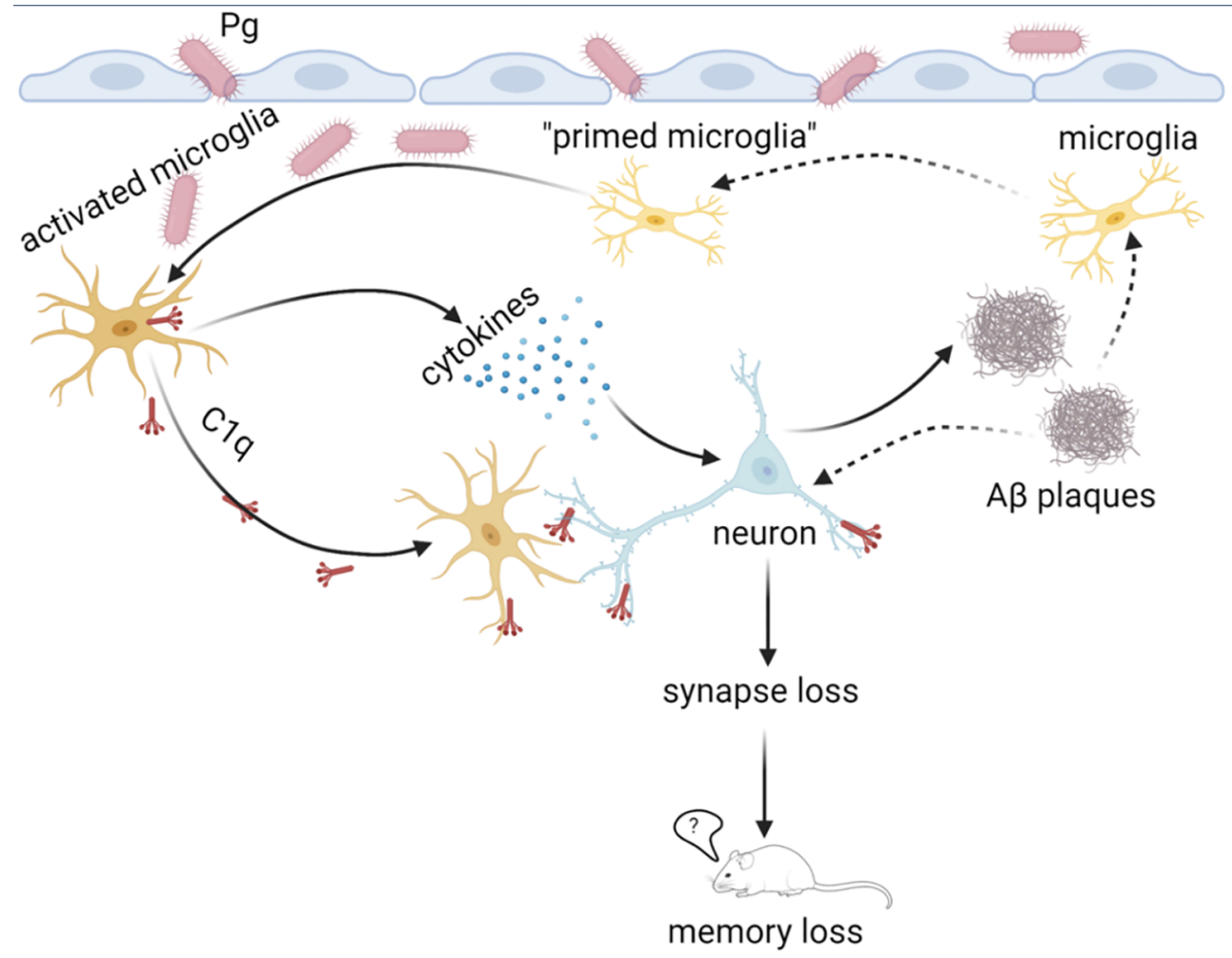

FIGURE 9 | Proposed "two-hit" model of AD progression in the presence of periodontitis. The accumulation of A $\beta$ in the brain with AD may serve as the first "hit" to prime microglia and induce low levels of complement activation and neuroinflammation. In the presence of periodontitis, periodontal pathogens may invade the brain and serve as the second "hit" to amplify neuroinflammation of the A $\beta$-primed microglia and facilitate synapse loss. Complement C1q is critical for Pg-mediated acceleration of AD progression by tagging synapses for microglia engulfment. This image was created by Biorender.com.

second "hit" to facilitate microglial overactivation and synapse loss in $\mathrm{AD}$ in the presence of periodontitis (Figure 9). Furthermore, periodontitis-induced overactivation of complement $\mathrm{Clq}$ is critical in aggravating microglial priming and activation, leading to an exacerbated neurodegeneration in $\mathrm{AD}$. Thus, simply reducing A $\beta$ burden alone without eliminating periodontal infection may not completely break a vicious cycle formed by $A \beta$ deposition, complement activation, and neuroinflammation in $\mathrm{AD}$ in the presence of periodontitis. Future studies will determine the regulation of microglia priming and if targeting certain complement components could ameliorate periodontitis and thus $\mathrm{AD}$ progression in the presence of periodontal infection. Knowledge obtained from these studies will fill the gap in our understanding of the association between periodontitis and $\mathrm{AD}$, and will pave the way for targeting microbial etiology to ameliorate the clinical manifestations of $\mathrm{AD}$ and lower $\mathrm{AD}$ prevalence.

\section{DATA AVAILABILITY STATEMENT}

The original contributions presented in the study are included in the article/Supplementary Material. Further inquiries can be directed to the corresponding author.

\section{ETHICS STATEMENT}

The animal study was reviewed and approved by University of Alabama at Birmingham Institutional Animal Care and Use Committee.

\section{AUTHOR CONTRIBUTIONS}

PZ conceptualized and supervised the study. XH planned and performed the experiments, and analyzed data. ZL assisted with the animal experiments and WL assisted with imaging processing and data analysis. $\mathrm{PZ}$ and $\mathrm{XH}$ wrote the manuscript. JK, SM, SB, LP-M, QW, and ER provided expertise and resources, and critically reviewed the manuscript. TS and TCS provided the App KI mice. All authors read and approved the final manuscript.

\section{FUNDING}

This work was supported by National Institute of Dental and Craniofacial Research (NIDCR) grant DE026465 (to PZ). ZL was supported by a NIDCR training grant R90 DE023056. UAB Comprehensive Flow Cytometry Core is supported by NIH P30 
AR048311 and P30 AI27667. UAB Behavior Assessment Core is supported by NIH P30 NS47466. Confocal images were taken at the UAB Comprehensive Neuroscience Center and the UAB Civitan International Research Center.

\section{ACKNOWLEDGMENTS}

We thank Gregory Harber for his technical assistance. We also thank Dr. Xin Xu from UAB Comprehensive Neuroscience

\section{REFERENCES}

1. Bateman R. Alzheimer's Disease and Other Dementias: Advances in 2014. Lancet Neurol (2015) 14(1):4-6. doi: 10.1016/S1474-4422(14) 70301-1

2. Chen Y, Dang M, Zhang Z. Brain Mechanisms Underlying Neuropsychiatric Symptoms in Alzheimer's Disease: A Systematic Review of Symptom-General and -Specific Lesion Patterns. Mol Neurodegener (2021) 16(1):38. doi: 10.1186/s13024-021-00456-1

3. Norton S, Matthews FE, Barnes DE, Yaffe K, Brayne C. Potential for Primary Prevention of Alzheimer's Disease: An Analysis of PopulationBased Data. Lancet Neurol (2014) 13(8):788-94. doi: 10.1016/S14744422(14)70136-X

4. Association. As. 2020 Alzheimer's Disease Facts and Figures. Alzheimers Dement (2020) 16:391-460. doi: 10.1002/alz.12068

5. Lamont RJ, Hajishengallis G. Polymicrobial Synergy and Dysbiosis in Inflammatory Disease. Trends Mol Med (2015) 21(3):172-83. doi: 10.1016/ j.molmed.2014.11.004

6. Hajishengallis G, Chavakis T. Local and Systemic Mechanisms Linking Periodontal Disease and Inflammatory Comorbidities. Nat Rev Immunol (2021) 21:426-40. doi: 10.1038/s41577-020-00488-6

7. Ide M, Harris M, Stevens A, Sussams R, Hopkins V, Culliford D, et al. Periodontitis and Cognitive Decline in Alzheimer's Disease. PloS One (2016) 11(3):e0151081. doi: 10.1371/journal.pone.0151081

8. Nascimento PC, Castro MML, Magno MB, Almeida A, Fagundes NCF, Maia LC, et al. Association Between Periodontitis and Cognitive Impairment in Adults: A Systematic Review. Front Neurol (2019) 10:323. doi: 10.3389/ fneur.2019.00323

9. Kamer AR, Pirraglia E, Tsui W, Rusinek H, Vallabhajosula S, Mosconi L, et al. Periodontal Disease Associates With Higher Brain Amyloid in Normaly Elderly. Neurobiol Aging (2015) 36:627-33. doi: 10.1016/j.neurobiolaging. 2014.10.038

10. Poole S, Singhrao SK, Kesavalu L, Curtis MA, Crean S. Determining the Presence of Periodontopathic Virulence Factors in Short-Term Postmortem Alzheimer's Disease Brain Tissue. J Alzheimers Dis (2013) 36(4):665-77. doi: 10.3233/JAD-121918

11. Dominy SS, Lynch C, Ermini F, Benedyk M, Marczyk A, Konradi A, et al. Porphyromonas Gingivalis in Alzheimer's Disease Brains: Evidence for Disease Causation and Treatment With Small-Molecule Inhibitors. Sci Adv (2019) 5(1):eaau3333. doi: 10.1126/sciadv.aau3333

12. Greenhalgh AD, David S, Bennett FC. Immune Cell Regulation of Glia During CNS Injury and Disease. Nat Rev Neurosci (2020) 21(3):139-52. doi: 10.1038/ s41583-020-0263-9

13. Efthymiou AG, Goate AM. Late Onset Alzheimer's Disease Genetics Implicates Microglial Pathways in Disease Risk. Mol Neurodegener (2017) 12(1):43. doi: 10.1186/s13024-017-0184-x

14. Hajishengallis G, Reis ES, Mastellos DC, Ricklin D, Lambris JD. Novel Mechanisms and Functions of Complement. Nat Immunol (2017) 18 (12):1288-98. doi: 10.1038/ni.3858

15. Ricklin D, Hajishengallis G, Yang K, Lambris JD. Complement: A Key System for Immune Surveillance and Homeostasis. Nat Immunol (2010) 11(9):78597. doi: $10.1038 /$ ni.1923

16. Hajishengallis G. Complement and Periodontitis. Biochem Pharmacol (2010) 80(12):1992-2001. doi: 10.1016/j.bcp.2010.06.017
Center for her help with the primary neuronal culture, and Dr. Yuechuan Chen from UAB Department of Oral \& Maxillofacial Surgery for his help with construction of lentivirus vectors.

\section{SUPPLEMENTARY MATERIAL}

The Supplementary Material for this article can be found online at: https://www.frontiersin.org/articles/10.3389/fimmu.2022. 816640/full\#supplementary-material

17. Patters MR, Niekrash CE, Lang NP. Assessment of Complement Cleavage in Gingival Fluid During Experimental Gingivitis in Man. J Clin Periodontol (1989) 16(1):33-7. doi: 10.1111/j.1600-051x.1989.tb01609.x

18. Hong S, Beja-Glasser VF, Nfonoyim BM, Frouin A, Li S, Ramakrishnan S, et al. Complement and Microglia Mediate Early Synapse Loss in Alzheimer Mouse Models. Science (2016) 352(6286):712-6. doi: 10.1126/science.aad8373

19. Morgan BP. Complement in the Pathogenesis of Alzheimer's Disease. Semin Immunopathol (2018) 40(1):113-24. doi: 10.1007/s00281-017-0662-9

20. Veerhuis R. Histological and Direct Evidence for the Role of Complement in the Neuroinflammation of AD. Curr Alzheimer Res (2011) 8(1):34-58 doi: $10.2174 / 156720511794604589$

21. Saito T, Matsuba Y, Mihira N, Takano J, Nilsson P, Itohara S, et al. Single App Knock-in Mouse Models of Alzheimer's Disease. Nat Neurosci (2014) 17 (5):661-3. doi: 10.1038/nn.3697

22. Zhao Y, Li Z, Su L, Ballesteros-Tato A, Katz J, Michalek SM, et al. Characterization and Regulation of Osteoclast Precursors Following Chronic Porphyromonas Gingivalis Infection. J Leukoc Biol (2020) 108 (4):1037-50. doi: 10.1002/jlb.1hi0620-230r

23. Poole S, Singhrao SK, Chukkapalli S, Rivera M, Velsko I, Kesavalu L, et al. Active Invasion of Porphyromonas Gingivalis and Infection-Induced Complement Activation in Apoe-/- Mice Brains. J Alzheimers Dis (2015) 43 (1):67-80. doi: 10.3233/JAD-140315

24. Baker PJ, Dixon M, Roopenian DC. Genetic Control of Susceptibility to Porphyromonas Gingivalis-Induced Alveolar Bone Loss in Mice. Infect Immun (2000) 68(10):5864-8. doi: 10.1128/iai.68.10.5864-5868.2000

25. Lecourtier L, Antal MC, Cosquer B, Schumacher A, Samama B, Angst MJ, et al. Intact Neurobehavioral Development and Dramatic Impairments of Procedural-Like Memory Following Neonatal Ventral Hippocampal Lesion in Rats. Neuroscience (2012) 207:110-23. doi: 10.1016/j.neuroscience.2012. 01.040

26. Shepherd JK, Grewal SS, Fletcher A, Bill DJ, Dourish CT. Behavioural and Pharmacological Characterisation of the Elevated "Zero-Maze" as an Animal Model of Anxiety. Psychopharmacol (Berl) (1994) 116(1):56-64. doi: 10.1007/ BF02244871

27. West MJ. Regionally Specific Loss of Neurons in the Aging Human Hippocampus. Neurobiol Aging (1993) 14(4):287-93. doi: 10.1016/01974580(93)90113-p

28. Gage GJ, Kipke DR, Shain W. Whole Animal Perfusion Fixation for Rodents. J Vis $\operatorname{Exp}$ (2012) 65:3564. doi: 10.3791/3564

29. Chen Y, Peng Y, Che P, Gannon M, Liu Y, Li L, et al. Alpha(2A) Adrenergic Receptor Promotes Amyloidogenesis Through Disrupting APP-Sorla Interaction. Proc Natl Acad Sci USA (2014) 111(48):17296-301. doi: 10. 1073/pnas.1409513111

30. Rajamohamedsait HB, Sigurdsson EM. Histological Staining of Amyloid and Pre-Amyloid Peptides and Proteins in Mouse Tissue. Methods Mol Biol (2012) 849:411-24. doi: 10.1007/978-1-61779-551-0_28

31. Potts EM, Coppotelli G, Ross JM. Histological-Based Stainings Using FreeFloating Tissue Sections. J Vis Exp (2020) 162:10.3791/61622. doi: 10.3791/ 61622

32. Ippolito DM, Eroglu C. Quantifying Synapses: An ImmunocytochemistryBased Assay to Quantify Synapse Number. J Vis Exp (2010) 45:2270. doi: $10.3791 / 2270$

33. Gmiterek A, Wojtowicz H, Mackiewicz P, Radwan-Oczko M, Kantorowicz M, Chomyszyn-Gajewska M, et al. The Unique Hmuy Gene Sequence as a 
Specific Marker of Porphyromonas Gingivalis. PloS One (2013) 8(7):e67719. doi: 10.1371 /journal.pone.0067719

34. Maeda H, Fujimoto C, Haruki Y, Maeda T, Kokeguchi S, Petelin M, et al. Quantitative Real-Time PCR Using Taqman and SYBR Green for Actinobacillus Actinomycetemcomitans, Porphyromonas Gingivalis, Prevotella Intermedia, Tetq Gene and Total Bacteria. FEMS Immunol Med Microbiol (2003) 39(1):81-6. doi: 10.1016/S0928-8244(03)00224-4

35. Singhrao SK, Chukkapalli S, Poole S, Velsko I, Crean SJ, Kesavalu L. Chronic Porphyromonas Gingivalis Infection Accelerates the Occurrence of AgeRelated Granules in Apoe(-)(/)(-) Mice Brains. J Oral Microbiol (2017) 9 (1):1270602. doi: 10.1080/20002297.2016.1270602

36. Barghorn S, Nimmrich V, Striebinger A, Krantz C, Keller P, Janson B, et al. Globular Amyloid Beta-Peptide Oligomer - a Homogenous and Stable Neuropathological Protein in Alzheimer's Disease. J Neurochem (2005) 95 (3):834-47. doi: 10.1111/j.1471-4159.2005.03407.x

37. Roque PJ, Costa LG. Co-Culture of Neurons and Microglia. Curr Protoc Toxicol (2017) 74:11 24 1-11 24 17. doi: 10.1002/cptx.32

38. Hilgenberg LG, Smith MA. Preparation of Dissociated Mouse Cortical Neuron Cultures. J Vis Exp (2007) 10):562. doi: 10.3791/562

39. DeTure MA, Dickson DW. The Neuropathological Diagnosis of Alzheimer's Disease. Mol Neurodegener (2019) 14(1):32. doi: 10.1186/s13024-019-0333-5

40. Chen GF, Xu TH, Yan Y, Zhou YR, Jiang Y, Melcher K, et al. Amyloid Beta: Structure, Biology and Structure-Based Therapeutic Development. Acta Pharmacol Sin (2017) 38(9):1205-35. doi: 10.1038/aps.2017.28

41. Heneka MT, Carson MJ, Khoury JE, Landreth GE, Brosseron F, Feinstein DL, et al. Neuroinflammation in Alzheimer's Disease. Lancet Neurol (2015) 14 (4):388-405. doi: 10.1016/s1474-4422(15)70016-5

42. Schafer DP, Stevens B. Microglia Function in Central Nervous System Development and Plasticity. Cold Spring Harb Perspect Biol (2015) 7(10): a020545. doi: 10.1101/cshperspect.a020545

43. Markovic SN, Inwards DJ, Frigas EA, Phyliky RP. Acquired C1 Esterase Inhibitor Deficiency. Ann Intern Med (2000) 132(2):144-50. doi: 10.7326/ 0003-4819-132-2-200001180-00009

44. Selkoe DJ. Alzheimer's Disease is a Synaptic Failure. Science (2002) 298 (5594):789-91. doi: 10.1126/science.1074069

45. Stephan AH, Madison DV, Mateos JM, Fraser DA, Lovelett EA, Coutellier L, et al. A Dramatic Increase of C1q Protein in the CNS During Normal Aging. J Neurosci: Off J Soc Neurosci (2013) 33(33):13460-74. doi: 10.1523/ JNEUROSCI.1333-13.2013

46. Chukkapalli S, Rivera-Kweh M, Gehlot P, Velsko I, Bhattacharyya I, Calise SJ, et al. Periodontal Bacterial Colonization in Synovial Tissues Exacerbates Collagen-Induced Arthritis in B10 RIII Mice. Arthritis Res Ther (2016) 18 (1):161. doi: 10.1186/s13075-016-1056-4

47. Scannapieco FA. Periodontal Inflammation: From Gingivitis to Systemic Disease? Compend Contin Educ Dent (2004) 25(7 Suppl 1):16-25.

48. Varatharaj A, Galea I. The Blood-Brain Barrier in Systemic Inflammation. Brain Behav Immun (2017) 60:1-12. doi: 10.1016/j.bbi.2016.03.010

49. Fonseca MI, Chu SH, Hernandez MX, Fang MJ, Modarresi L, Selvan P, et al. Cell-Specific Deletion of C1qa Identifies Microglia as the Dominant Source of C1q in Mouse Brain. J Neuroinflamm (2017) 14(1):48. doi: 10.1186/s12974017-0814-9

50. Fonseca MI, Ager RR, Chu SH, Yazan O, Sanderson SD, LaFerla FM, et al. Treatment With a C5ar Antagonist Decreases Pathology and Enhances Behavioral Performance in Murine Models of Alzheimer's Disease. J Immunol (2009) 183(2):1375-83. doi: 10.4049/jimmunol.0901005

51. Fonseca MI, Zhou J, Botto M, Tenner AJ. Absence of C1q Leads to Less Neuropathology in Transgenic Mouse Models of Alzheimer's Disease. J Neurosci (2004) 24(29):6457-65. doi: 10.1523/JNEUROSCI.090104.2004
52. Hajishengallis G, Maekawa T, Abe T, Hajishengallis E, Lambris JD. Complement Involvement in Periodontitis: Molecular Mechanisms and Rational Therapeutic Approaches. Adv Exp Med Biol (2015) 865:57-74. doi: 10.1007/978-3-319-18603-0_4

53. Beikler T, Peters U, Prior K, Eisenacher M, Flemmig TF. Gene Expression in Periodontal Tissues Following Treatment. BMC Med Genomics (2008) 1:30. doi: $10.1186 / 1755-8794-1-30$

54. Hajishengallis G, Hajishengallis E, Kajikawa T, Wang B, Yancopoulou D, Ricklin D, et al. Complement Inhibition in Pre-Clinical Models of Periodontitis and Prospects for Clinical Application. Semin Immunol (2016) 28(3):285-91. doi: 10.1016/j.smim.2016.03.006

55. Prinz M, Erny D, Hagemeyer N. Ontogeny and Homeostasis of CNS Myeloid Cells. Nat Immunol (2017) 18(4):385-92. doi: 10.1038/ni.3703

56. Fiebich BL, Batista CRA, Saliba SW, Yousif NM, de Oliveira ACP. Role of Microglia Tlrs in Neurodegeneration. Front Cell Neurosci (2018) 12:329. doi: $10.3389 /$ fncel.2018.00329

57. Zhang X, Kracht L, Lerario AM, Dubbelaar ML, Brouwer N, Wesseling EM, et al. Epigenetic Regualtion of Innate Immune Memory in Microglia. bioRxiv (2021). doi: 10.1101/2021.05.30.446351

58. Wendeln AC, Degenhardt K, Kaurani L, Gertig M, Ulas T, Jain G, et al. Innate Immune Memory in the Brain Shapes Neurological Disease Hallmarks. Nature (2018) 556(7701):332-8. doi: 10.1038/s41586-018-0023-4

59. Myneni SR, Settem RP, Connell TD, Keegan AD, Gaffen SL, Sharma A. TLR2 Signaling and Th2 Responses Drive Tannerella Forsythia-Induced Periodontal Bone Loss. J Immunol (2011) 187(1):501-9. doi: 10.4049/jimmunol.1100683

60. Liu S, Liu Y, Hao W, Wolf L, Kiliaan AJ, Penke B, et al. TLR2 Is a Primary Receptor for Alzheimer's Amyloid Beta Peptide to Trigger Neuroinflammatory Activation. J Immunol (2012) 188(3):1098-107. doi: 10.4049/jimmunol.1101121

61. Li JW, Zong Y, Cao XP, Tan L, Tan L. Microglial Priming in Alzheimer's Disease. Ann Transl Med (2018) 6(10):176. doi: 10.21037/atm.2018.04.22

62. Gosztyla ML, Brothers HM, Robinson SR. Alzheimer's Amyloid-Beta Is an Antimicrobial Peptide: A Review of the Evidence. J Alzheimers Dis (2018) 62 (4):1495-506. doi: 10.3233/JAD-171133

63. Spires-Jones TL, Hyman BT. The Intersection of Amyloid Beta and Tau at Synapses in Alzheimer's Disease. Neuron (2014) 82(4):756-71. doi: 10.1016/ j.neuron.2014.05.004

64. Stevens B, Allen NJ, Vazquez LE, Howell GR, Christopherson KS, Nouri N, et al. The Classical Complement Cascade Mediates CNS Synapse Elimination. Cell (2007) 131(6):1164-78. doi: 10.1016/j.cell.2007.10.036

\section{Conflict of Interest: SB is the CSO \& Co-Founder of CNine Biosolutions, LLC.}

The remaining authors declare that the research was conducted in the absence of any commercial or financial relationships that could be construed as a potential conflict of interest.

Publisher's Note: All claims expressed in this article are solely those of the authors and do not necessarily represent those of their affiliated organizations, or those of the publisher, the editors and the reviewers. Any product that may be evaluated in this article, or claim that may be made by its manufacturer, is not guaranteed or endorsed by the publisher.

Copyright $\odot 2022$ Hao, Li, Li, Katz, Michalek, Barnum, Pozzo-Miller, Saito, Saido, Wang, Roberson and Zhang. This is an open-access article distributed under the terms of the Creative Commons Attribution License (CC BY). The use, distribution or reproduction in other forums is permitted, provided the original author(s) and the copyright owner(s) are credited and that the original publication in this journal is cited, in accordance with accepted academic practice. No use, distribution or reproduction is permitted which does not comply with these terms. 